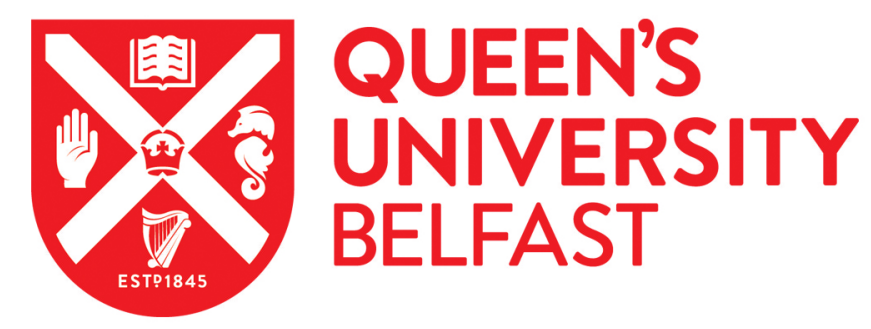

\title{
Bitcoin is not the New Gold - A comparison of volatility, correlation, and portfolio performance
}

Klein, T., Thu, H. P., \& Walther, T. (2018). Bitcoin is not the New Gold - A comparison of volatility, correlation, and portfolio performance. International Review of Financial Analysis, 59, 105-116.

https://doi.org/10.1016/j.irfa.2018.07.010

Published in:

International Review of Financial Analysis

Document Version:

Peer reviewed version

Queen's University Belfast - Research Portal:

Link to publication record in Queen's University Belfast Research Portal

Publisher rights

Copyright 2018 Elsevier.

This manuscript is distributed under a Creative Commons Attribution-NonCommercial-NoDerivs License

(https://creativecommons.org/licenses/by-nc-nd/4.0/), which permits distribution and reproduction for non-commercial purposes, provided the author and source are cited

\section{General rights}

Copyright for the publications made accessible via the Queen's University Belfast Research Portal is retained by the author(s) and / or other copyright owners and it is a condition of accessing these publications that users recognise and abide by the legal requirements associated with these rights.

Take down policy

The Research Portal is Queen's institutional repository that provides access to Queen's research output. Every effort has been made to ensure that content in the Research Portal does not infringe any person's rights, or applicable UK laws. If you discover content in the Research Portal that you believe breaches copyright or violates any law, please contact openaccess@qub.ac.uk. 


\title{
Bitcoin is not the New Gold - A Comparison of Volatility, Correlation, and Portfolio Performance ${ }^{\text {th }}$
}

\author{
Tony Klein ${ }^{\mathrm{a}, \mathrm{b}, *}$, Hien Pham Thu ${ }^{\mathrm{c}}$, Thomas Walther ${ }^{\mathrm{a}, \mathrm{d}}$ \\ ${ }^{a}$ Faculty of Business and Economics, Technische Universität Dresden, Germany \\ ${ }^{b}$ Queen's Management School, Queen's University Belfast, UK \\ ${ }^{c}$ School of Business and Economics, Humboldt-Universität zu Berlin, Germany \\ ${ }^{d}$ Institute for Operations Research and Computational Finance, University of St. Gallen, Switzerland
}

\begin{abstract}
Cryptocurrencies such as Bitcoin are establishing themselves as an investment asset and are often named the New Gold. This study, however, shows that the two assets could barely be more different. Firstly, we analyze and compare conditional variance properties of Bitcoin and Gold as well as other assets and find differences in their structure. Secondly, we implement a BEKK-GARCH model to estimate time-varying conditional correlations. Gold plays an important role in financial markets with flight-to-quality in times of market distress. Our results show that Bitcoin behaves as the exact opposite and it positively correlates with downward markets. Lastly, we analyze the properties of Bitcoin as portfolio component and find no evidence for stable hedging capabilities. We conclude that Bitcoin and Gold feature fundamentally different properties as assets and linkages to equity markets. Our results hold for the broad cryptocurrency index CRIX. As of now, Bitcoin does not reflect any distinctive properties of Gold other than asymmetric response in variance.
\end{abstract}

Keywords: Bitcoin, Correlation, Cryptocurrencies, Gold, Asymmetry JEL classification: C10; C58; G11

\section{Introduction}

The popularity of cryptocurrencies has risen significantly since Nakamoto (2008) introduced the concept of Bitcoin. Cryptocurrencies embody innovative technology, highsecurity architecture, prosperity in functionalities, and investment opportunity as an asset whats makes them attractive for computer scientists, venture capitalists as well as investors. However, the decentralization and unregulated markets add an additional layer of uncertainty to its pricing and projection of application. Examples are the closures

\footnotetext{
${ }^{\star}$ We thank Wolfgang Härdle and Hermann Locarek-Junge and two anonymous reviewers for their helpful remarks. We are also thankful to the participants of the "Cryptocurrencies in a Digital Economy" workshop (HU Berlin), in particular Simon Trimborn, for their valuable suggestions and comments.

${ }^{*}$ Corresponding Author, Mail: t.klein@qub.ac.uk.
} 
of exchanges in China based on changing legal situation which causes worldwide price reactions of large magnitude. Especially in the last years, large shocks and a bubble-like price movement are observable. The market capitalization of cryptocurrencies reached its peak at USD 831bn in January 7, 2018 which is comparable to the market valuation of the biggest companies in the world, like Apple or Alphabet. The market with currently 1622 cryptocurrencies (as of May 2018) is dominated by Bitcoin, Ethereum, and Ripple which capture around 63 percent of the total market capitalization.1 What started as an experiment by decentralized governance enthusiasts is becoming an investment vehicle for investors and a core business model for companies as a new and innovative way of payment. The general idea of this distributed ledger technology is transferred to many other fields in finance. For a detailed introduction into the key concepts of cryptocurrencies and Bitcoin, we refer to Bariviera et al. (2017), Chuen (2015), Dwyer (2015), Elendner et al. (2018), and Härdle et al. (2018).

Cryptocurrencies, in particular Bitcoin, have been labeled the New Gold by some media, banks, and also data providers throughout the last years. ${ }^{2}$ While this view might be motivated by fast and high returns in a gold rush like environment, we compare Gold and Bitcoin from an econometric perspective and focus on the economic aspects of cryptocurrencies as an investment asset. We address the question how cryptocurrencies can be classified based on volatility behavior and how they are correlated with already established asset classes. Thus, we do not explore the cryptocurrency market itself as in Brandvold et al. (2015) or Ciaian et al. (2017), but the relationship with other asset classes. Cryptocurrencies are not directly linked to any monetary policy instruments or fundamentals. Therefore, analysis of common factors between these virtual currencies and other financial asset classes is challenging. On the regulatory side, the Commodity Futures Trading Commission (CFTC) has officially declared virtual money a commodity, just like crude oil or Gold. The Commission states that Bitcoin as a virtual currency is a digital representation of value that functions as a medium of exchange, a unit of account, and/or a store of value, but does not have legal tender status in any jurisdiction. Bitcoin and other cryptocurrencies are distinctly different from fiat currencies, which are the coin and paper money that are designated as legal tender, circulated, and are customarily used and accepted as a medium of exchange.

The analysis in this paper is divided into three parts. Firstly, we investigate the volatility behavior of cryptocurrencies in comparison to stock indices and commodities. According to Blau (2017), the high volatility of Bitcoin until 2014 is not related to speculative trading. This is in contradiction to Cheah \& Fry (2015) and Cheung et al. (2015), who find Bitcoin to build speculative bubbles in the same time frame. In the present study,

\footnotetext{
${ }^{1}$ The calculations are based on data from www.coinmarketcap.com retrieved May 16, 2018.

${ }^{2}$ See for example articles on Bloomberg, Forbes, and $\mathrm{CNN}$.
} 
we aim to classify cryptocurrencies within the conventional asset classes by analyzing the volatility. Conrad et al. (2018), Catania \& Grassi (2017), Dyhrberg (2016), Katsiampa (2017), and Chu et al. (2017) use univariate volatility models to analyze the volatility structure of Bitcoin and other cryptocurrencies. Conrad et al. (2018) examine the drivers of long-term volatility of Bitcoin and compare them to other assets class, e.g. Gold. The authors find that Bitcoin volatility is distinct compared to other asset classes. Here, we focus especially on the stylized facts long memory and asymmetry. The property of long memory of a financial time series is also referred to as persistence and describes long lasting, i.e. slowly decaying autocorrelation effects in conditional returns or volatility (Baillie, 1996). Many types of financial time series are reported to attribute long memory in their variance; e.g. individual stocks, stock indices, commodities, and foreign exchange rates (i.a. Baillie, 1996, Bollerslev \& Mikkelsen, 1996, Chkili et al., 2014, Walther et al., 2017). The property of asymmetric volatility is explained by the empirical phenomenon when negative (positive) returns are associated with upward (downward) revision of the conditional volatility (Engle \& Ng, 1993, Zakoian, 1994). In the stock market, this asymmetry effect results from the leverage effect (Black, 1976, Christie, 1982) and the volatility feedback effect (Campbell \& Hentschel, 1992). Regarding cryptocurrencies, Dyhrberg (2016) reports an insignificant leverage effect of Bitcoin. Catania \& Grassi (2017), however, find an inverse leverage effect as well as significant long memory in the most prominent cryptocurrencies.

Secondly, this research explores the hedge and safe haven capabilities of cryptocurrencies in comparison to Gold by means of a dynamic correlation analysis. We apply the definition of hedge, diversifier, and safe haven given in Baur \& Lucey (2010). An asset which is uncorrelated or negatively correlated with another asset is defined as a hedge whereas a safe haven asset is uncorrelated or negatively correlated with other assets in distressed markets only. Assets which are a diversifier are positively (on average), but not perfectly correlated to other assets. As diversification opportunities are diminishing in market turmoil, investors seek to find assets which are uncorrelated or negatively correlated with their portfolio's assets. There is a wide range of literature investigating Gold as hedge and safe haven against assets such as stocks, bonds, and US Dollar (i.a. Baur \& Lucey, 2010, Baur \& McDermott, 2010, 2016, Capie et al., 2005). However, on more recent data, the safe haven property seems to be dissipating (Klein, 2017). Meanwhile, research on cryptocurrencies' purpose for investment is growing. For example, Dyhrberg (2016) compares the hedging capabilities of Bitcoin and Gold against stocks and US Dollar. Bouri et al. (2017b) conclude that Bitcoin may only be used as a diversifier, but not as a hedge. However, Bouri et al. (2017a) and Demir et al. (2018) note that Bitcoin can be used as short-term hedge in extreme market situations. The results of Corbet et al. (2018) suggest that cryptocurrencies are not connected to conventional markets and may offer short-term diversification benefits. Guesmi et al. (2018) finds short positions 
in Bitcoin to have hedging potential. We discuss short positions at a later point. In our analysis, we assess the potential of cryptocurrencies as hedge and safe haven. We examine the correlation of Bitcoin with Gold, Silver, the oil price WTI, and the three equity indices S\&P 500, MSCI World, and MSCI Emerging Markets 50. The diversification effects provided by cryptocurrencies are investigated in the context of time-varying correlation. Lastly, we apply a portfolio analysis which emphasizes the behavior of Gold and Bitcoin in times of distress.

Our findings indicate that Bitcoin is not the new Gold. Its volatility dynamics share some aspects with Gold and Silver, however, from a portfolio perspective, Bitcoin does not serve as a safe-haven which is a prominent feature of Gold.

The structure of this paper is organized as follows. Section 2 presents the methodology of the study in which we outline the comparison based on univariate volatility modeling, multivariate variance-covariance modeling, and from a portfolio perspective. The data sets and preliminary tests are introduced in Section 3. Section 4 presents the findings of the comparison and discusses them. The paper concludes in Section 5 .

\section{Methodology}

\subsection{Properties of Conditional Variance}

In order to characterize the volatility structure of assets, we employ (Generalized) Autoregressive Conditional Heteroskedasticity ((G)ARCH, Engle, 1982, Bollerslev, 1986) models. Here, we focus especially on two stylized facts: the leverage effect and long memory. Thus, for our volatility regression we use two models which are able to depict these two properties. Namely, we use the Asymmetric Power ARCH (APARCH, Ding et al., 1993 ) and the Fractionally Integrated APARCH (FIAPARCH, Tse, 1998) model. Formally, we run a first order autoregressive model on the asset's returns, $r_{t}$, with Student's $t$ distributed errors of zero mean with conditional variance $h_{t}$ which then reads

$$
\begin{aligned}
r_{t} & =\theta_{0}+\theta_{1} r_{t-1}+\varepsilon_{t}, \\
\varepsilon_{t} & =\sqrt{h_{t}} \eta_{t},
\end{aligned}
$$

with $\eta_{t} \sim$ St- $t_{\nu}(0,1)$ i.i.d. for all $t=1, \ldots, n$. Table 1 summarizes the definitions of $h_{t}$ for both models. The non-negative constraints $\omega, \beta \geq 0$ have to hold. Further, FIAPARCH requires $0 \leq \beta \leq \phi+d$ and $0 \leq d \leq 1-2 \phi$. The leverage parameter $\gamma \in(-1,1)$ measures the impact of asymmetric behavior of the residuals on the conditional volatility. The power parameter $\delta$ determines whether it is appropriate to model the variance $(\delta=2)$, the standard deviation $(\delta=1)$, or any other, real-valued degree. Ding et al. (1993) show that autocorrelation of $\left|r_{t}\right|^{\delta}$ of a time series $r_{t}$ with $\delta$ close to 1 is larger and longer than other values for $\delta$ and thus indicate the behavior of long memory in volatility. Another possibility to measure long memory is given by fractionally integrated models such as 
Table 1: Overview of univariate conditional variance models.

\begin{tabular}{llcc}
\hline Model & Definition & Asymmetry & Long memory \\
\hline $\operatorname{APARCH}(1,1)$ & $h_{t}^{\delta / 2}=\omega+\alpha\left(\left|\varepsilon_{t-1}\right|-\gamma \varepsilon_{t-1}\right)^{\delta}+\beta h_{t-1}^{\delta / 2}$ & Yes & Indirectly \\
$\operatorname{FIAPARCH}(1, d, 1)$ & $h_{t}^{\delta / 2}=\omega+\left(1-\beta L-(1-\phi L)(1-L)^{d}\right)\left(\left|\varepsilon_{t}\right|-\gamma \varepsilon_{t}\right)^{\delta}+\beta h_{t-1}^{\delta / 2}$ & Yes & Yes \\
\hline
\end{tabular}

FIAPARCH. The long memory parameter $d \in(0,1)$ reflects the persistence of shocks, which rises when $d$ approaches zero (Davidson, 2004) ? $^{3}$

\subsection{Dynamic Correlation Modeling}

Analogously to the univariate modeling, we compare the properties of Bitcoin and Gold from a multivariate perspective in terms of their relationship to other markets and assets. Let $R_{t}$ be a $k$-dimensional vector of observations at time $t$, denoted as

$$
R_{t}=\mu_{t}+\varepsilon_{t}
$$

where $\mu_{t}$ is a $k$-dimensional conditional mean structure. For the $k$-dimensional vector $\varepsilon_{t}$, we assume $\varepsilon_{t} \mid \mathcal{F}_{t-1} \sim \mathcal{N}\left(0, \mathbf{H}_{t}\right)$. We model conditional heteroskedasticity with

$$
\varepsilon_{t}=\mathbf{H}_{t}^{1 / 2} \zeta_{t}
$$

where $\mathbf{H}_{t}$ denotes the $(k \times k)$-sized conditional variance matrix and $\zeta_{t}$ refers to a $k$ dimensional vector of standard normally distributed and i.i.d. random variables with zero mean and $\mathbb{E}\left[\zeta_{t}, \zeta_{t}^{\prime}\right]=I_{k}$. In Eq. (1), the matrix process $\mathbf{H}_{t}$ can be determined in several ways; directly, with the Vector Error Correction model as suggested in (Bollerslev et al. 1988) or with the Baba-Engle-Kraft-Kroner (BEKK-GARCH) model (Engle \& Kroner, 1995), which is outlined subsequently $4^{4}$ We apply the diagonal BEKK model which is a sufficient compromise between parameter dimensionality and sample size. In the BEKK model, the conditional variance-covariance matrix $\mathbf{H}_{t}$ is defined as

$$
\begin{aligned}
\mathbf{H}_{t}= & \mathbf{C}^{\top} \mathbf{C}+\mathbf{A}_{1}^{\top} \varepsilon_{t-1} \varepsilon_{t-1}^{\top} \mathbf{A}+\mathbf{G}^{\top} \mathbf{H}_{t-1} \mathbf{G} \\
= & {\left[\begin{array}{cc}
c_{11} & 0 \\
c_{12} & c_{22}
\end{array}\right]\left[\begin{array}{cc}
c_{11} & c_{12} \\
0 & c_{22}
\end{array}\right]+\operatorname{diag}\left[a_{11}, a_{22}\right]^{\top}\left[\begin{array}{cc}
\varepsilon_{1, t-1}^{2} & \varepsilon_{1, t-1} \varepsilon_{2, t-1} \\
\varepsilon_{1, t-1} \varepsilon_{2, t-1} & \varepsilon_{2, t-1}^{2}
\end{array}\right] \operatorname{diag}\left[a_{11}, a_{22}\right] } \\
& \quad+\operatorname{diag}\left[g_{11}, g_{22}\right]^{\top} \mathbf{H}_{t-1} \operatorname{diag}\left[g_{11}, g_{22}\right],
\end{aligned}
$$

\footnotetext{
${ }^{3}$ Note that we use the approach of Klein \& Walther (2017) to estimate the parameter of fractionally integrated variance models. We implement an $\operatorname{ARCH}(\infty)$ truncation lag of 1000 .

${ }^{4}$ Furthermore, the conditional covariance matrix can be modeled by decomposing $\mathbf{H}_{t}$ into conditional standard deviations and correlations, presented in Engle (2002) and referred to as the Dynamic Conditional Correlation (DCC) model. As we observe relatively extreme returns and variances in cryptocurrencies (in comparison to other conventional assets), our DCC implementations are prone to instabilities and convergence issues.
} 
where $\mathbf{A}, \mathbf{G}$, and $\mathbf{C}$ are $k \times k$ parameter matrices and $\mathbf{C}$ is lower triangular. In the diagonal version of the BEKK defined in Eq. (3), matrices $\mathbf{A}$ and $\mathbf{G}$ are diagonal matrices. Nonnegativity, or positive-definiteness of $\mathbf{H}_{t}$ is achieved with relatively weak conditions Engle \& Kroner, 1995).

Focusing on the most important linkages to other markets, we calculate the pairwise correlation between Gold and Bitcoin to other assets by setting $k=2$ and apply the BEKK to centralized residuals. In Section 4, correlation plots are smoothed with a SavitzkyGolay filter (Savitzky \& Golay, 1964).

\subsection{Portfolio-Based Comparison}

In order to further investigate the hedging capabilities of Bitcoin and Gold, we implement a ex-post portfolio-based comparison with three steps:

1. We calculate the time-varying weights $w_{t}$ of a two component minimum-variance portfolio of an asset with an market index, e.g. Bitcoin with S\&P 500. The weights are optimized for each point in time of our sample by

$$
\begin{aligned}
& \min _{w_{t}} \quad w_{t}^{\prime} \mathbf{H}_{t} w_{t} \\
& \text { s.t. } \quad w_{t}^{\prime} 1_{k}=1
\end{aligned}
$$

where the covariance matrix $\mathbf{H}_{t}$ is obtained from the BEKK framework in Section 4.2 .

2. We calculate the historical Value-of-Risk of the S\&P 500 or MSCI World over the whole sample period, denoted by $\mathrm{VaR}_{q}$, i.e. we take the empirical quantile $q$ at $1 \%$, $5 \%$, and $10 \%$ of the returns $r_{t}$ of that index. To obtain the $\mathrm{VaR}_{0.01}$ of an index, for example, we sort all returns of that index in an ascending order. If the index has $T$ returns, the Value-at-Risk is the $\lceil T \times 0.01\rceil$-th return in that list. Henceforth, we define all points in time

$$
t^{*}:=\left\{t \mid r_{t}<\mathrm{VaR}_{q}\right\}
$$

as times where the index is in distress.

3. Finally, we evaluate the two-component portfolio, consisting of an index and Gold or Bitcoin, with returns $r_{t}^{\mathrm{PF}}$ calculated from the dynamic weights $w_{t}$ from step 1 . With a special focus on distressed times $t^{*}$, we calculate the mean of the portfolio returns during these times as

$$
\tilde{r}_{D}=\frac{1}{\left|t^{*}\right|} \sum_{m \in t^{*}} r_{m}^{\mathrm{PF}}
$$

which can be seen as a kind of Expected Shortfall or Conditional Value-at-Risk. 


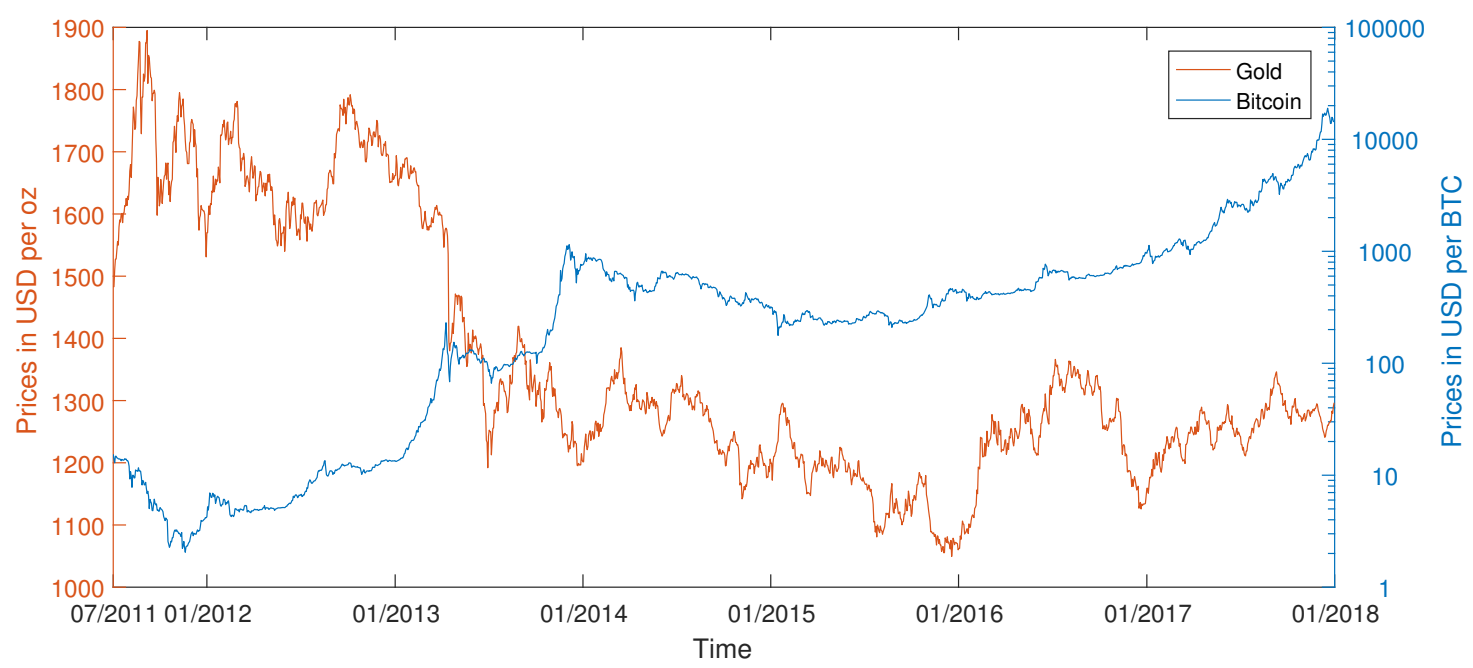

Figure 1: Prices of Gold and Bitcoin(in logarithmic scale) from July 2011 to December 2017, $n=1695$.

This approach allows us to scrutinize whether the asset can serve as (temporary) hedge, i.e. hedge the equity index during times of turmoil and thus, lower the impact of distressed times on the index on average.

\section{Data and Preliminary Analysis}

In our analysis, we include a data set of six times series: the cryptocurrency Bitcoin, Gold and Silver prices in USD per oz, crude oil prices for the West Texas Intermediate (WTI), the S\&P 500 index, MSCI World and the MSCI Emerging Markets 50 index. The time series cover the period from 2011-07-01 to 2017-12-31 and are synchronized 5 From daily closing prices, we calculate returns as the natural logarithmic price differences, $r_{t}=100 \times \log \left(P_{t} / P_{t-1}\right)$. For conventional assets, we take the closing price or index points of each trading day. Data for these assets are obtained from Datastream with GMT timestamp. For Bitcoin, we retrieve the data from coindesk.com, also with GMT timestamp, and process the price at the end of the day since cryptocurrencies are traded continuously. Since Bitcoin is also traded on weekends, we only consider the prices during the week to synchronize our dataset $\sqrt[6]{6}$ Hence, we obtain 1695 returns for each time series. Prices for Gold and Bitcoin are plotted in Fig. 1. This figure puts the extreme price increases of Bitcoin in 2017 into perspective of its price history. In order to visualize this dramatic increase, prices are plotted on a logarithmic scale.

Tab. 2 summarizes the descriptive statistics and some first time series tests for the six assets. Here, Bitcoin returns have the highest mean and standard deviation by far.

\footnotetext{
${ }^{5}$ We choose this time window to avoid most of the zero-return trading days in the beginning of Bitcoin trading.

${ }^{6}$ Note that we also tested weekend price interpolation for the conventional assets. However, this introduced some bias to the model estimation by low or virtually zero returns over the weekend.
} 
Table 2: Descriptive statistics for Bitcoin and financial daily return time series for Jul 2, 2011 to Dec 31, 2017, $n=1695$ observations.

\begin{tabular}{|c|c|c|c|c|c|c|c|}
\hline & Bitcoin & Gold & Silver & WTI & S\&P 500 & MSCI World & MSCI EM50 \\
\hline Mean & 0.4037 & -0.0079 & -0.0407 & -0.0267 & 0.0489 & 0.0363 & 0.0245 \\
\hline Std. Dev. & 5.7577 & 1.0499 & 1.7633 & 2.1369 & 0.8859 & 0.8069 & 0.9444 \\
\hline Min. & -44.3784 & -9.5962 & -12.9970 & -10.7263 & -6.8801 & -5.2465 & -5.1962 \\
\hline Max. & 49.9663 & 4.8387 & 7.5760 & 11.6213 & 4.6344 & 4.1164 & 3.9169 \\
\hline Skewness & -0.3406 & -0.6239 & -0.7120 & 0.0956 & -0.5306 & -0.6622 & -0.2586 \\
\hline Kurtosis & 14.2658 & 10.1569 & 8.5263 & 6.3419 & 9.0885 & 8.8237 & 5.1929 \\
\hline Jarque Bera & $8996.3259^{* * *}$ & $3727.4769^{* * *}$ & $2300.1225^{* * *}$ & $791.3631^{* * *}$ & $2697.5676^{* * *}$ & $2519.1784^{* * *}$ & $358.5180^{* * *}$ \\
\hline Ljung Box (25) & $60.4956^{* * *}$ & $37.9578^{* *}$ & $38.4509^{* *}$ & $38.9043^{* *}$ & $68.2019^{* * *}$ & $66.5574^{* * *}$ & $109.0498^{* * *}$ \\
\hline ARCH (25) & $264.1286^{* * *}$ & $52.2211^{* * *}$ & $148.6979^{* * *}$ & $263.3804^{* * *}$ & $497.2257^{* * *}$ & $379.9198^{* * *}$ & $248.6839^{* * *}$ \\
\hline $\mathrm{ADF}$ & $-40.0953^{* * *}$ & $-41.9713^{* * *}$ & $-42.6236^{* * *}$ & $-45.2808^{* * *}$ & $-43.5181^{* * *}$ & $-36.4768^{* * *}$ & $-33.6676^{* * *}$ \\
\hline
\end{tabular}

Note: Std. Dev. is the standard deviation, Min. and Max. are minimum and maximum of the time series. ARCH(25) is the test for autoregressive conditional heteroskedasticity by Engle (1982) at the 25th lag. ADF is the Augmented Dickey-Fuller test for unit root.

Moreover, the three commodities, Gold, Silver, and WTI, have negative mean returns between $-0.04 \%$ and $-0.008 \%$. The three equity indices, S\&P 500, MSCI World, and MSCI EM50, have slightly positive mean returns. However, among the five conventional assets, the WTI has the highest daily standard deviation with $2.14 \%$. Bitcoin has a daily standard deviation of $5.76 \%$ which is more than two times of the risk of WTI. Skewness, Kurtosis, and subsequently the Jarque Bera test result in the conclusion that none of the six time series are Normally distributed. The Ljung-Box and the ARCH test suggest autocorrelation in the returns and their volatility. Lastly, the Augmented Dickey-Fuller test rejects the hypothesis of a unit root in the data and we assume all time series to be stationary.

We illustrate the descriptive statistics of Bitcoin and Gold in Fig. 2. The left panel compares the return series of both assets and elucidates the differences in volatility level. The right panel captures the high kurtosis of both series in a histogram. It is obvious that Bitcoin's tails are much more pronounced than the tails of the density of Gold returns.

Since literature suggests bubble behavior in prices of Bitcoin, we briefly analyze the time series as outlined in Kruse et al. (2018) and estimate

$$
\log \left(P_{t}\right)=a+b \log \left(P_{t-1}\right)+\varepsilon_{t}
$$

on a rolling 30-day window..$^{7}$ Explosive behavior, indicated by $\bar{b}>1$ for the respective 30-day window, is detected on isolated occasions which are spread throughout the history of the Bitcoin price series. We note that not only the price increase of November and December 2017 is detected as explosive behavior but also other significant-yet smaller scale - price jumps, e.g. during the beginning of 2013. These jumps might explain the

\footnotetext{
${ }^{7}$ For a discussion on bias-reduction with indirect inference of this estimation method for shorter rolling windows, we refer to Kruse et al. (2018).
} 

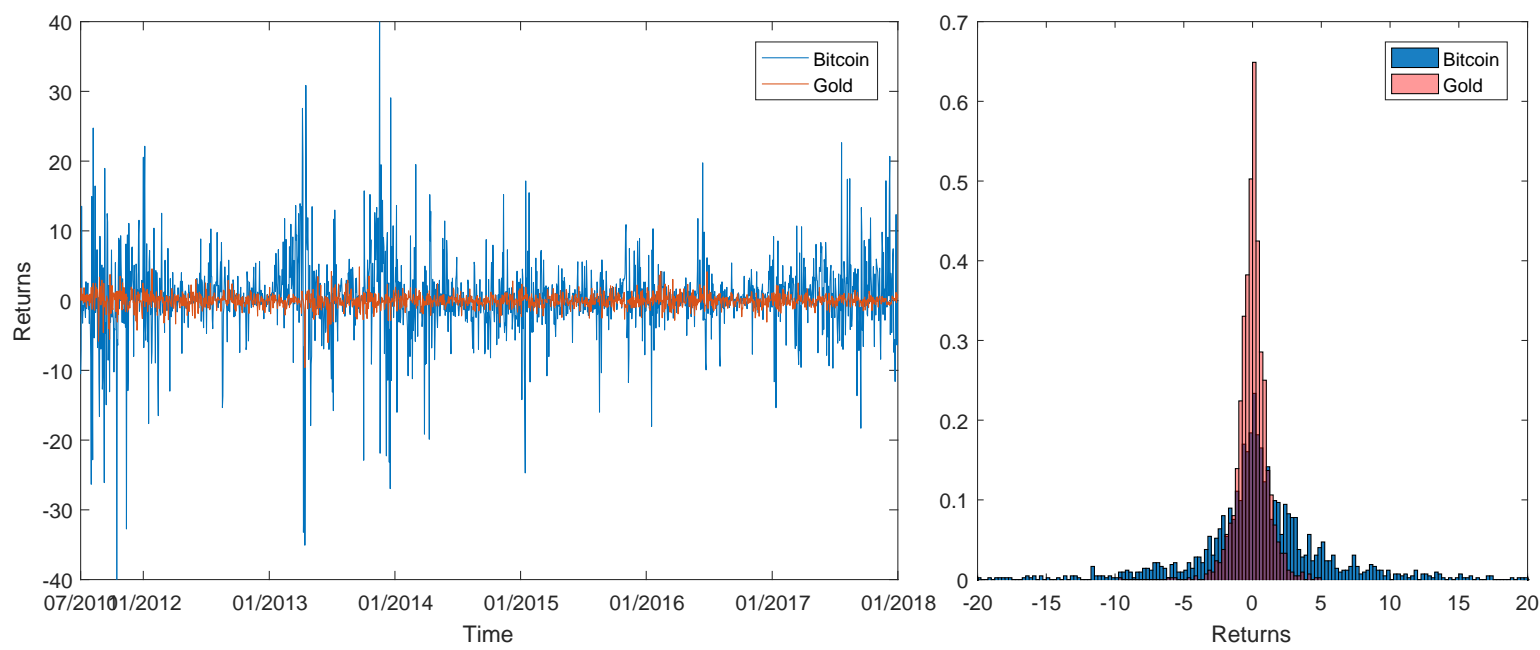

Figure 2: Plots of the daily return series of Gold and Bitcoin (left) and resulting histogram (right). For readability, the ordinate of the return plot is limited to $[-40,40]$ and the abscissa of the histogram is limited to $[-20,20]$. A small number of returns of Bitcoin is exceeding these limits.

Table 3: Unconditional pairwise Pearson correlation matrix for the sample period Jul 2, 2011 to Dec 31, 2017.

\begin{tabular}{l|ccccccc}
\hline & Bitcoin & Gold & Silver & WTI & S\&P 500 & MSCI World & MSCI EM50 \\
\hline Bitcoin & 1.0000 & 0.0459 & 0.0071 & 0.0158 & 0.0491 & 0.0457 & 0.0042 \\
Gold & & 1.0000 & 0.6877 & 0.0655 & -0.0366 & 0.0591 & 0.0840 \\
Silver & & & 1.0000 & 0.1954 & 0.0775 & 0.2028 & 0.2181 \\
WTI & & & & 1.0000 & 0.3481 & 0.3800 & 0.2705 \\
S\&P 500 & & & & & 1.0000 & 0.9148 & 0.5041 \\
MSCI World & & & & & & 1.0000 & 0.6706 \\
MSCI EM50 & & & & & & & 1.0000 \\
\hline
\end{tabular}

high volatility of Bitcoin as well as the high mean return.

As a first indication for the correlation between the six assets, Tab. 3 presents the unconditional pairwise Pearson correlations. We find that Bitcoin has only a slightly positive correlation with the other assets, from which Gold, S\&P 500 and MSCI World have the highest correlation with Bitcoin between 0.045 and 0.049. The MSCI EM50 index has the lowest correlation with Bitcoin. Interestingly, Gold has a slightly negative correlation with S\&P 500, but a positive correlation of 0.059 with MSCI World, which is similar to the correlation of Bitcoin to MSCI World. However, since this is only the average correlation over the whole sample, we derive the time-varying specifics from the BEKK model in Section 4.2 .

\section{Results}

\subsection{Comparison of Conditional Variance Dynamics}

In a first step, we analyze and compare the univariate volatility structure of the six assets and apply the APARCH and FIAPARCH model. These ARCH models can depict long memory and asymmetric effects. We estimate the parameters of an AR(1)-APARCH and -FIAPARCH model with Student's $t$ distributed errors with $\nu$ degrees-of-freedom. 
Table 4: Estimation results from APARCH model with $n=1695$ observations. Statistically significant parameters are indicated with asterisk $*, * *, * * *$ for $10 \%, 5 \%$, and $1 \%$ level of significance.

\begin{tabular}{l|ccccccc}
\hline & Bitcoin & Gold & Silver & WTI & S\&P 500 & MSCI World & MSCI EM50 \\
\hline$\theta_{0}$ & $0.3521^{* * *}$ & -0.0051 & -0.0009 & -0.0150 & $0.0582^{* * *}$ & $0.0399^{* * *}$ & 0.0205 \\
$\theta_{1}$ & -0.0364 & -0.0164 & $-0.0607^{* * *}$ & $-0.0696^{* * *}$ & $-0.0670^{* * *}$ & $0.0812^{* * *}$ & $0.1777^{* * *}$ \\
\hline$\omega$ & 0.8581 & 0.0054 & 0.0362 & $0.0089^{* *}$ & $0.0287^{* * *}$ & $0.0206^{* *}$ & $0.0197^{* *}$ \\
$\alpha$ & $0.1694^{* * *}$ & 0.0135 & 0.0027 & $0.0336^{* * *}$ & $0.1094^{* * *}$ & $0.0932^{* * *}$ & $0.0250^{*}$ \\
$\beta$ & $0.8306^{* * *}$ & $0.9721^{* * *}$ & $0.9847^{* * *}$ & $0.9663^{* * *}$ & $0.8906^{* * *}$ & $0.9061^{* * *}$ & $0.9210^{* * *}$ \\
$\gamma$ & $-0.1972^{* * *}$ & -0.0368 & $-0.1748^{* *}$ & $0.9995^{* * *}$ & $0.9995^{* * *}$ & $0.9929^{* * *}$ & $0.9982^{* * *}$ \\
$\delta$ & $2.3065^{* * *}$ & $2.7788^{* *}$ & $4.0000^{* * *}$ & $1.1554^{* * *}$ & $0.9004^{* * *}$ & $0.9007^{* * *}$ & $2.0480^{* * *}$ \\
\hline$\nu$ & $2.7895^{* * *}$ & $4.0728^{* * *}$ & $3.0291^{* * *}$ & $7.4318^{* * *}$ & $4.9035^{* * *}$ & $5.6001^{* * *}$ & $12.9275^{* * *}$ \\
\hline LL & -4757.74 & -2276.95 & -3144.77 & -3387.27 & -1806.08 & -1641.80 & -2123.75 \\
BIC & 9574.96 & 4613.39 & 6349.02 & 6834.02 & 3671.64 & 3343.09 & 4306.99 \\
\hline Jarque Bera & $14297.2533^{* * *}$ & $18806.0706^{* * *}$ & $2814.1535^{* * *}$ & $151.5134^{* * *}$ & $465.5090^{* * *}$ & $1091.3124^{* * *}$ & $29.4072^{* * *}$ \\
Ljung Box (25) & $55.2186^{* * *}$ & $36.6557^{* *}$ & $38.1835^{* *}$ & 18.0121 & 22.9455 & 24.1004 & 21.6948 \\
ARCH (25) & $83.4615^{* * *}$ & 4.8511 & $42.1987^{* *}$ & 21.5143 & $57.9416^{* * *}$ & 28.3117 & 26.3618 \\
\hline
\end{tabular}

Analyzing the APARCH parameter in Tab. 4, we find Bitcoin to be more similar to Gold and Silver than to WTI, S\&P 500, MSCI World or MSCI EM50 at first glance. Even though Gold does not have a significant leverage parameter $\gamma$, the two metals and Bitcoin share the same sign. All three assets tend to have higher volatility, if the former day's residual was positive, which is known as an inverse leverage effect - a prominent feature of Gold and Silver. This is in contradiction to the findings of Dyhrberg (2016), who does not find a significant asymmetric effect. Our own calculations suggest that this is due to the fact that we use the Student's $t$-distribution to account for heavy tails present in the distribution of returns 8 The sensitivity of results regarding the underlying distribution is also discussed in Baur et al. (2017) whose findings are in line with those presented above. Thus, we conjecture that using a better suited distribution reveals the property of asymmetric effects for Bitcoin as shown by Catania \& Grassi (2017). On the contrary, the other four assets have a high positive $\gamma$ indicating that volatility rises if last day's return is negative. Similarly, the power parameter $\delta$ for WTI, S\&P 500, and MSCI World is around 1, i.e. modeling the standard deviation appears better rather than the variance. The estimated $\delta$ for Gold and Bitcoin on the other hand, is in a range between 2.3 and 2.78. The ARCH test reveals that APARCH seems unable to diminish the whole autocorrelation structure in the volatility of Bitcoin.

The estimated parameters for the FIAPARCH are shown in Tab. 5. All time series reveal some degree of long memory, which is most pronounced in Gold and Silver. The Bitcoin does have a significant long memory effect, but is not as persistent as the two metal commodities. We find an asymmetric effect for Bitcoin's volatility which is comparable to the ones of Gold and Silver as shown before for APARCH. Again, the power parameter $\delta$ is of similar size for Bitcoin, Gold, and Silver. While it is between 2 and 3 for the

\footnotetext{
${ }^{8}$ When repeating the regression with normally distributed errors, we can confirm and replicate the findings of Dyhrberg (2016).
} 
Table 5: Estimation results from FIAPARCH model with $n=1695$ observations. Statistically significant parameters are indicated with asterisk $*, * *, * * *$ for $10 \%, 5 \%$, and $1 \%$ level of significance.

\begin{tabular}{|c|c|c|c|c|c|c|c|}
\hline & Bitcoin & Gold & Silver & WTI & S\&P 500 & MSCI World & MSCI EM50 \\
\hline$\theta_{0}$ & $0.3105^{* * *}$ & -0.0041 & -0.0008 & -0.0091 & $0.0588^{* * *}$ & $0.0463^{* * *}$ & 0.0148 \\
\hline$\theta_{1}$ & -0.0012 & -0.0176 & $-0.0564^{* * *}$ & $-0.0680^{* * *}$ & $-0.0632^{* * *}$ & $0.0793^{* * *}$ & $0.1778^{* * *}$ \\
\hline$\omega$ & 0.8022 & 0.0890 & 0.6805 & $0.3037^{* * *}$ & $0.1492^{* *}$ & 0.0941 & $0.1112^{* *}$ \\
\hline$\alpha$ & 0.1081 & $0.3198^{* * *}$ & $0.4418^{* *}$ & 0.0000 & $0.1452^{* *}$ & 0.0749 & 0.0981 \\
\hline$d$ & $0.7838^{* * *}$ & $0.3046^{* * *}$ & $0.1163^{*}$ & $0.9855^{* * *}$ & $0.5390^{* * *}$ & $0.4580^{* * *}$ & $0.2836^{* * *}$ \\
\hline$\beta$ & $0.6024^{* *}$ & $0.6207^{* * *}$ & $0.5178^{* *}$ & $0.9468^{* * *}$ & $0.5510^{* * *}$ & $0.4670^{* * *}$ & $0.3397^{*}$ \\
\hline$\gamma$ & $-0.1360^{* *}$ & -0.1522 & $-0.1961^{*}$ & $0.4547^{* * *}$ & $0.9198^{* * *}$ & $0.7219^{* * *}$ & $0.5129^{* * *}$ \\
\hline$\delta$ & $2.6932^{* * *}$ & $2.1678^{* * *}$ & $3.0000^{* * *}$ & $1.4318^{* * *}$ & $1.1730^{* * *}$ & $1.2801^{* * *}$ & $1.6842^{* * *}$ \\
\hline$\nu$ & $2.8546^{* * *}$ & $3.9589^{* * *}$ & $3.0201^{* * *}$ & $7.2083^{* * *}$ & $5.3033^{* * *}$ & $6.1160^{* * *}$ & $12.0667^{* * *}$ \\
\hline LL & -4719.27 & -2279.77 & -3146.65 & -3391.91 & -1783.92 & -1634.84 & -2125.46 \\
\hline $\mathrm{BIC}$ & 9505.46 & 4626.46 & 6360.21 & 6850.73 & 3634.75 & 3336.61 & 4317.85 \\
\hline Jarque Bera & $10471.5744^{* * *}$ & $9792.5785^{* * *}$ & $1204.6351^{* * *}$ & $199.7367^{* * *}$ & $560.8414^{* * *}$ & $1370.1336^{* * *}$ & $36.4122^{* * *}$ \\
\hline Ljung Box (25) & $66.7220^{* * *}$ & $36.8645^{*}$ & $35.6686^{*}$ & 17.2492 & 19.7676 & 21.1447 & 21.2311 \\
\hline ARCH (25) & 19.2901 & 5.7398 & 26.6395 & 18.5606 & 19.1779 & 11.6784 & 26.5850 \\
\hline
\end{tabular}

cryptocurrency and the two metals, the other three assets have estimated parameters between 1 and 1.5. The last parameter we want to focus on is the degree-of-freedom of the underlying Student's $t$ distribution. Here, the small $\nu$ for Bitcoin, Gold, and Silver (between 2.85 and 3.95) correspond to the high kurtosis of these assets shown in Tab. 2. Moreover, we conclude that the FIAPARCH model seems appropriate for all seven assets, since it is able to diminish the autocorrelation in the volatility, i.e. the ARCH test is not rejected.

Finally, when comparing the BIC of APARCH and FIAPARCH as a model choice criteria for our sample, we conclude that the three commodities - Gold, Silver, WTIand the emerging market index MSCI EM50 are better modeled with APARCH which purely models asymmetry, while the remaining three assets - Bitcoin, S\&P 500, and MSCI World - have a better in-sample performance with FIAPARCH which additionally models long memory.

Hence, from the perspective of the volatility structure, Bitcoin shows evidence that it has a similar asymmetric response observed in Gold and Silver. The long memory parameter indicates a different persistence or long memory, which might be due to the short and volatile history of Bitcoin and cryptocurrencies in general.

\subsection{Correlation of Bitcoin to Financial Markets}

Based on the BEKK-GARCH framework, we estimate dynamic correlations between the considered assets.9 We begin our analysis by reporting the findings for Gold. In view of the flight-to-quality phenomenon (Hammoudeh et al., 2010) and safe haven categorization (Baur \& Lucey, 2010), time of market turmoil or distress is of particular interest. However, our sample from July 2011 to December 2017 is characterized by relatively stable growth

\footnotetext{
${ }^{9}$ Parameter estimates for all BEKK combinations in this section are available upon request.
} 
rates of financial markets, proxied in this study by the S\&P 500 and the MSCI World index. For the S\&P 500, we identify only two short periods of market distress and significant, shock-like declines during the stock sell-off in August 2015 and again late 2015/early 2016 which is connected to crude oil prices dropping below $\$ 30$ per barrel. Fig. 3 plots the dynamic correlations of Gold and S\&P 500 returns. The shaded area in blue marks significant market downturns. Several conclusions can be drawn from the estimates. Most importantly, we see that the correlations drop to negative values during market distress. In the first downturn, we observe a change from positive to negative correlation and a turnaround in the subsequent market recovery. The drop in correlation during the second market distress situation (end of 2015, beginning of 2016) is quite significant as (non-smoothed) correlations drop from 0.3 to -0.4 within a few trading days. This behavior is expected if the safe haven property holds true and is clearly in favor of the flight-to-quality hypothesis. Given that our sample does not include a major and prolonged market downturn (such as the Financial Crisis), these two smaller shocks suggest that the the flight-to-quality is still intact. More surprisingly, the plot might also reveal that Gold has not been a safe haven according to the definition of Baur \& Lucey (2010) relative to the S\&P 500 in recent years. From 2014 on, we mainly observe negative correlations in times of stable upward movements of the S\&P 500. According to the definitions of Baur \& Lucey (2010), Gold then acts more like a hedge than a safe haven in recent years.

For the MSCI World index, the picture is somewhat different; we observe the same turn to negative correlations in times of market downturn. However, the correlation is mainly positive, in particular between 2012 and 2014, when Gold was very volatile. ${ }^{10}$

Turning to time-varying correlations of Bitcoin and the S\&P 500, plotted in Fig. 4, we firstly observe that the BEKK-GARCH correlation is extremely volatile and alternating between positive and negative values. A possible reason for this jump-like behavior might be the different absolute level of variance of the time series, where Bitcoin is characterized by very high and erratic returns, see Fig. 2. In the beginning of our sample, approximately until the end of 2013, the correlations are unstable and the alternating character becomes apparent when comparing the smoothing algorithm to actual correlation values. The erratic path makes an application infeasible during these times. This could be caused by the BEKK model itself or by the low prices of Bitcoin and a higher-than-usual volatility cluster which can also be observed in Fig. 2. However, we also note that correlations become slightly less alternating and erratic from 2014 on. Henceforth, the correlation is negative in general with a few positive spikes in the smoothed path. Non-smoothed values peak up to 0.5 and get as low as -0.4 .

What makes the Bitcoin - S\&P 500 correlation fundamentally different from the cor-

\footnotetext{
${ }^{10}$ Additional plots are available in the Appendix.
} 


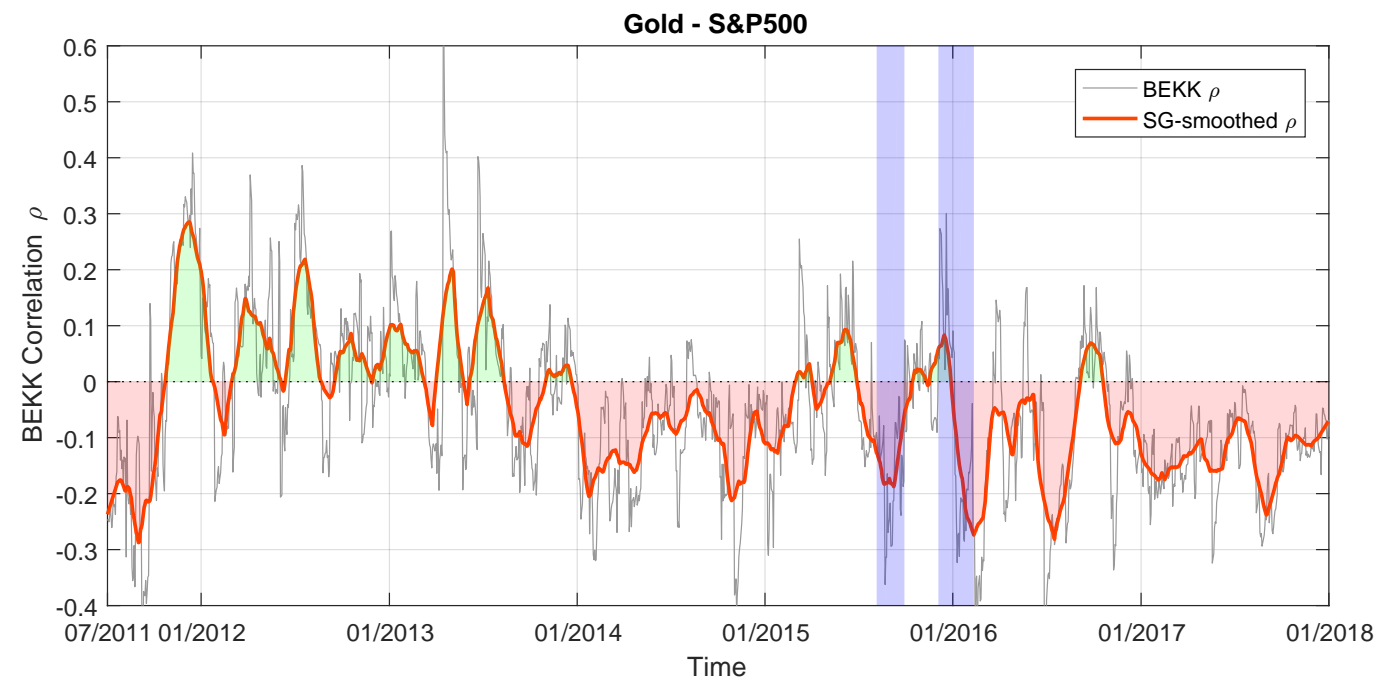

Figure 3: Dynamic correlations of Gold and S\&P 500 returns obtained with the BEKK-GARCH between July 2, 2011 and December 31, 2017, $n=1695$. Unfiltered correlations are plotted in gray, SavitzkyGolay-smoothing is plotted in red. Times of market distress is highlighted in blue.

relations of Gold and the index is the behavior during market distress. Interestingly, correlations are steeply increasing from negative to a positive relationship while the index is in a downward movement. This indicates that Bitcoin follows the downturn, which is observable in the raw as well as smoothed correlations in Fig. 4. The same behavior holds for the Bitcoin - MSCI World correlations. While Gold prices increase in the flight-to-quality, Bitcoin prices are decreasing with the markets.

To further highlight the differences, Fig. 5 visualizes the smoothed correlations of Gold and Bitcoin with the S\&P 500. Interestingly, the movements in correlations appear to be mirrored from 2015 on, while being negative on average. This falls into the time where Bitcoin is becoming more popular and price increases begin to accelerate. From the joint plot, it becomes clear that Bitcoin, viewed as an asset, behaves differently than Gold. Comparing the correlations of Gold and Bitcoin with the MSCI World, plotted in the Appendix, the mirrored movements are more emphasized and span over different signs. It appears that as soon as correlations of Gold and the MSCI World turn positive, Bitcoin correlations become negative and vice versa. Similar behavior is observable for the linkages to Silver, while the Gold - Silver correlation is naturally very high, and other commodities such as the WTI ${ }^{11}$ For correlations of the MSCI EM50 index, we observe similar correlations of Gold and Bitcoin with this index from the second half of 2015 to approximately the third quarter of 2016. During these times, Bitcoin quickly turned to negative correlations during distress in the markets of this index. As we have an intact flight-to-quality for Gold, we hence observe a temporal hedging situation. Before 2015 and from 2016:Q4 we observe the same mirroring of correlations as for the S\&P 500 and

\footnotetext{
${ }^{11}$ The pots of the correlation of Bitcoin with MSCI World, MSCI EM50, and WTI can be found in the Appendix.
} 


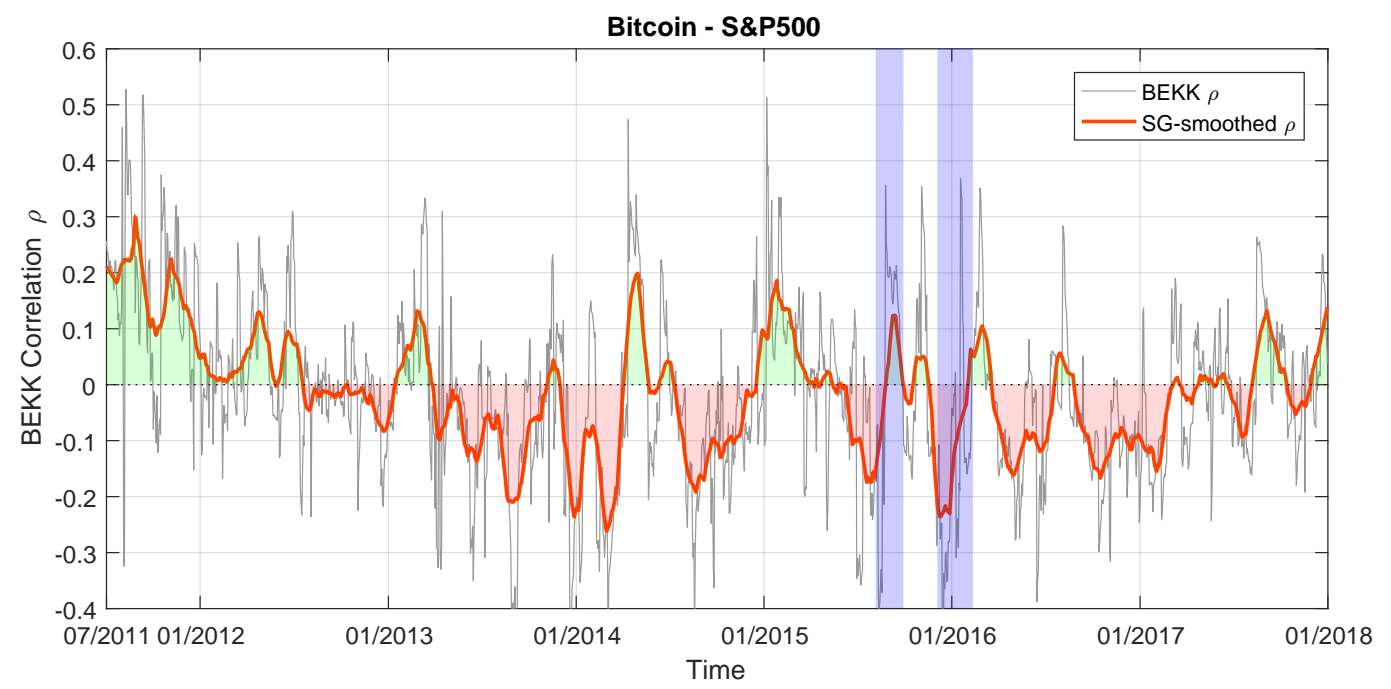

Figure 4: Dynamic correlations of Bitcoin and S\&P 500 returns obtained with the BEKK-GARCH between July 2, 2011 and December 31, 2017, $n=1695$. Unfiltered correlations are plotted in gray, Savitzky-Golay-smoothing is plotted in red. Times of market distress is highlighted in blue.

the MSCI World index.

Rounding up the analysis, Fig. 6 plots the dynamic correlations of Bitcoin and Gold prices. Interestingly, we observe a coupling effect in 2013 during the price decay of Gold. In 2014, we see some decoupling in the first half and positive correlations in the second half. End of 2013, Bitcoin spikes for the first time at around 1150 US Dollar and is in a decline during 2014, accompanied by some minor price recoveries. For Gold, prices recover from $1200 \mathrm{USD} / \mathrm{oz}$ to almost $1400 \mathrm{USD} / \mathrm{oz}$ in the first quarter while being generally decreasing throughout the year. This volatile period of Gold prices continues in 2015 while Bitcoin has relatively small price movements (relative to its own price history and volatility clustering). Hence we observe lower correlations which are somewhat stable. Focusing on 2017 with the Bitcoin price explosion beginning in the second quarter, Bitcoin and Gold are uncorrelated on average in the second and third quarter. In the fourth quarter, they couple again as we first observe strong price increases and shortly after price drops in Bitcoin that correlate with upward Gold price movements. We conclude that Bitcoin and Gold feature no stable correlation. Their return relationship is characterized by positive and negative spikes with no general tendency. One would assume this correlation to be positive and stable if Bitcoin is believed to be similar to Gold. If we compare Gold with Silver, another precious metal utilized as investment, we observe high and stable correlations.

Concluding our correlation analysis, we find Gold to be a hedge rather than a safe haven in recent years. Bitcoin, on the other hand, behaves completely different, especially from 2015 on. The cryptocurrency couples with markets during bearish environments, with correlations rapidly turning to positive values in these times. This holds true for both the S\&P 500 and the MSCI World index. During the last two years, we also observe 


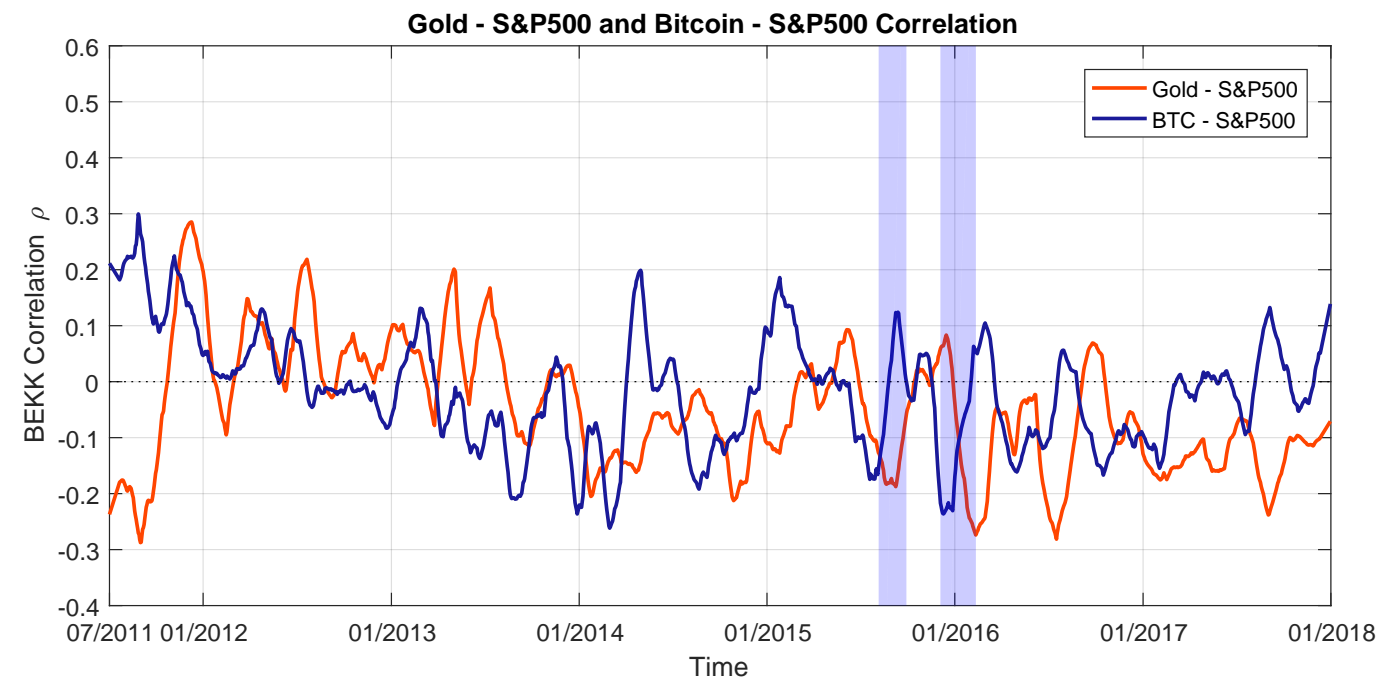

Figure 5: Smoothed correlations of Bitcoin and Gold returns with S\&P 500 returns obtained with the BEKK-GARCH between July 2, 2011 and December 31, 2017, $n=1695$. Times of market distress is highlighted in blue.

inverse movements of correlations of Gold and Bitcoin with these two indices. While correlations increase for Gold, Bitcoin correlations decrease to the same market and vice versa. This is a clear indication that Bitcoin and Gold have different connectedness to markets. However, we observe a temporal similarity of Bitcoin and Gold correlations with the MSCI EM50 index from mid-2015 to mid-2016. This effect is short-lived and dissipates after to mirrored correlations as in other markets. This effect could be due to the high acceptance of cryptocurrencies in the countries comprising the emerging markets index e.g. China. Applying the categorizations of Baur \& Lucey $(2010)$, we find Bitcoin to fit neither of them as we observe phases of positive and negative correlations, quickly alternating, as well as a positive correlation in market turmoil which argues against safe haven and hedging properties. This supports findings of Bouri et al. (2017b) based on data up to December 2015, that identify no safe haven or hedging properties against the assets in the present study.

\subsection{Portfolio-based Test of Hedging Property}

In this part, we analyze the hedging property of Bitcoin and Gold. The portfolios under examination are: Bitcoin/S\&P 500, Gold/S\&P 500, Bitcoin/MSCI World, Gold/MSCI World, Bitcoin/MSCI EM50, and Gold/MSCI EM50. In the following, we proceed as outlined in Section 2.3.

Firstly, we calculate the time-varying portfolio weights of the two component portfolios. The weights for the four portfolios are presented in Panel A of Tab. 6. Additionally, we illustrate the weights for the two portfolios with the S\&P 500 index in Fig. 7. It can be seen that the Gold proportion has a high variation within the portfolios with the two equity indices. This results in extreme cases where Gold tends to have almost $90 \%$ of the portfolio or is even short sold. The average Gold weight is $36.98 \%$ for S\&P 500, 30.88\% 


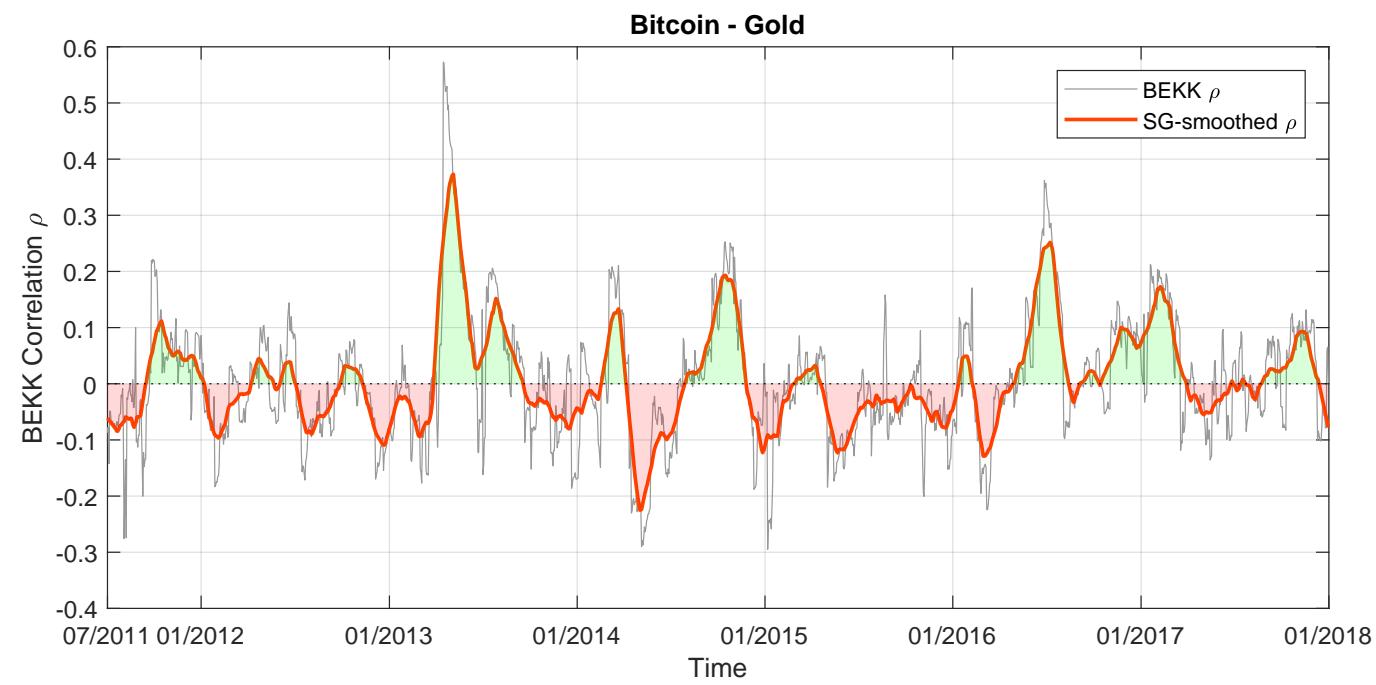

Figure 6: Dynamic correlations of Bitcoin and Gold returns obtained with the BEKK-GARCH between July 2, 2011 and December 31, 2017, $n=1695$. Unfiltered correlations are plotted in gray, SavitzkyGolay-smoothing is plotted in red.

for MSCI World, and $42.70 \%$ for MSCI EM50, respectively. Confirming the results of Guesmi et al. (2018), we find that Bitcoin only has a small proportion of a joint portfolio with the three stock indices and averages between $2.92 \%$ and $4.78 \%$, while having a standard deviation of about the same size. Obviously, this behavior stems from the high volatility of Bitcoin returns. For some periods for Gold and for Bitcoin, we obtain short positions, which can be seen by the minimum weights and in Fig. 7. The possibility to short Bitcoin is only a very recent development, gaining popularity with the introduction of Bitcoin futures on the CBOE and CME in December 2017. Until then, short-selling in the portfolio composition should be restricted. However, this also eliminates previously mentioned hedging possibilities by shorting Bitcoin investments. Given a functioning and liquid futures exchange, negative weights in Bitcoin investments should be seen as a possible investment opportunity in the future in view of portfolio variance reduction.

Secondly, the historical Value-at-Risk measures are determined and given in Panel B of Tab. 6. We find that the values for the S\&P 500 are slightly lower than for the MSCI World. The MSCI EM50 index has the lowest 5\% and 10\% Value-at-Risk measures. However, the extreme case of $1 \%$ is still above the Value-at-Risk of the S\&P 500.

Lastly, we use the calculated Value-at-Risk values to determine times of distress for the two equity markets and evaluate how a portfolio including Bitcoin or Gold reacts in these times of turmoil. The Panel $\mathrm{C}$ in Tab. 6 reports the average return, the volatility, and the average return of the portfolios for the times when the index is below the Valueat-Risk of that index. More specifically, we report a $100 \%$ investment in the portfolio compared with the minimum-variance portfolios. From the results in Panel C, we can draw the following two conclusions:

1) Over the whole sample, the minimum-variance combination of the indices with 
Table 6: Statistics for the minimum-variance portfolios for Bitcoin between Jul 2, 2011 and Dec 31, 2017.

\begin{tabular}{|c|c|c|c|c|c|c|c|c|c|}
\hline \multicolumn{10}{|c|}{ Panel A: Descriptive statistics of the portfolio weights } \\
\hline & \multicolumn{3}{|c|}{ S\&P 500} & \multicolumn{3}{|c|}{ MSCI World } & \multicolumn{3}{|c|}{ MSCI EM50 } \\
\hline & Bitcoin & \multicolumn{2}{|c|}{ Gold } & Bitcoin & \multicolumn{2}{|c|}{ Gold } & Bitcoin & \multicolumn{2}{|c|}{ Gold } \\
\hline Mean & 0.0369 & \multirow{4}{*}{\multicolumn{2}{|c|}{$\begin{array}{c}0.3698 \\
0.1368 \\
-0.0554 \\
0.8896\end{array}$}} & 0.0292 & \multirow{4}{*}{\multicolumn{2}{|c|}{$\begin{array}{c}0.3088 \\
0.1451 \\
-0.0429 \\
0.7883\end{array}$}} & 0.0478 & \multirow{4}{*}{\multicolumn{2}{|c|}{$\begin{array}{c}0.4270 \\
0.1157 \\
-0.1208 \\
0.7363\end{array}$}} \\
\hline Std. Dev. & 0.0403 & & & 0.0334 & & & 0.0439 & & \\
\hline Min. & -0.0850 & & & -0.0487 & & & -0.0486 & & \\
\hline Max. & 0.2203 & & & 0.1585 & & & 0.1929 & & \\
\hline \multicolumn{10}{|c|}{ Panel B: Value-at-Risk measures } \\
\hline & \multicolumn{3}{|c|}{ S\&P 500} & \multicolumn{3}{|c|}{ MSCI World } & \multicolumn{3}{|c|}{ MSCI EM50 } \\
\hline $\begin{array}{l}\operatorname{VaR}_{0.01} \\
\operatorname{VaR}_{0.05} \\
\operatorname{VaR}_{0.10} \\
\end{array}$ & \multicolumn{3}{|c|}{$\begin{array}{l}-2.5438 \\
-1.4159 \\
-0.9019 \\
\end{array}$} & \multicolumn{3}{|c|}{$\begin{array}{l}-2.3171 \\
-1.2454 \\
-0.8031\end{array}$} & \multicolumn{3}{|c|}{$\begin{array}{l}-2.5096 \\
-1.5707 \\
-1.1353\end{array}$} \\
\hline \multicolumn{10}{|c|}{ Panel C: Hedging Properties } \\
\hline & $\mathrm{S} \& \mathrm{P} 500$ & Bitcoin & Gold & MSCI World & Bitcoin & Gold & MSCI EM50 & Bitcoin & Gold \\
\hline Return & 0.0489 & 0.0547 & 0.0251 & 0.0363 & 0.0399 & 0.0239 & 0.0245 & 0.0370 & 0.0118 \\
\hline Volatility & 0.8859 & 0.9044 & 0.6483 & 0.8069 & 0.8174 & 0.6434 & 0.9444 & 0.9361 & 0.7265 \\
\hline Return|VaR 0.01 & -3.5755 & -3.6577 & -1.0105 & -3.4736 & -3.4840 & -1.1856 & -3.2653 & -3.0775 & -1.0866 \\
\hline Return|VaR 0.05 & -2.1881 & -2.2189 & -1.0195 & -2.0255 & -2.0267 & -1.1387 & -2.1592 & -2.0828 & -1.1383 \\
\hline Return $\mid \mathrm{VaR}_{0.10}$ & -1.6597 & -1.6619 & -0.8616 & -1.5264 & -1.5147 & -0.8835 & -1.7452 & -1.6628 & -1.0018 \\
\hline
\end{tabular}

Bitcoin slightly increases the average return as well as the volatility of the returns. Only for the combination with the MSCI EM50 index, the volatility of the minimum-variance portfolio remains almost unchanged. On the contrary, the minimum-variance portfolios of Gold and the indices decrease both, average return and volatility.

2) During the time where the equity indices are under distress, i.e. where the return of the index is smaller than the Value-at-Risk calculated in Panel B of Tab. 6, Bitcoin does not provide any kind of hedge. For the S\&P 500 and MSCI World, the minimum-variance combinations of the equity indices with Bitcoin lead to even lower average returns compared to a sole investment in the index, except for the $10 \%$ Value-at-Risk of MSCI World. Only the combination with the MSCI EM50 index leads to a slightly higher returns. On the other hand, Gold provides that hedge, which confirms the findings of the previous section. Gold may not fully protect from market drawdowns, but the hedging properties are clearly pronounced. The minimum-variance portfolios of Gold and the indices have a higher average return during times under distress.

Hence, we conclude from our ex-post portfolio exercise that in contrast to Gold, Bitcoin does not provide a hedge for equity investments.

\subsection{Robustness Check with Cryptocurrency Index}

In order to test whether our results hold for other cryptocurrencies, we repeat our analysis with the broad, market-weighted cryptocurrency index CRIX (Trimborn \& Härdle, 2016). We retrieve the index from July 31, 2014 to December 31, 2017 from the website 


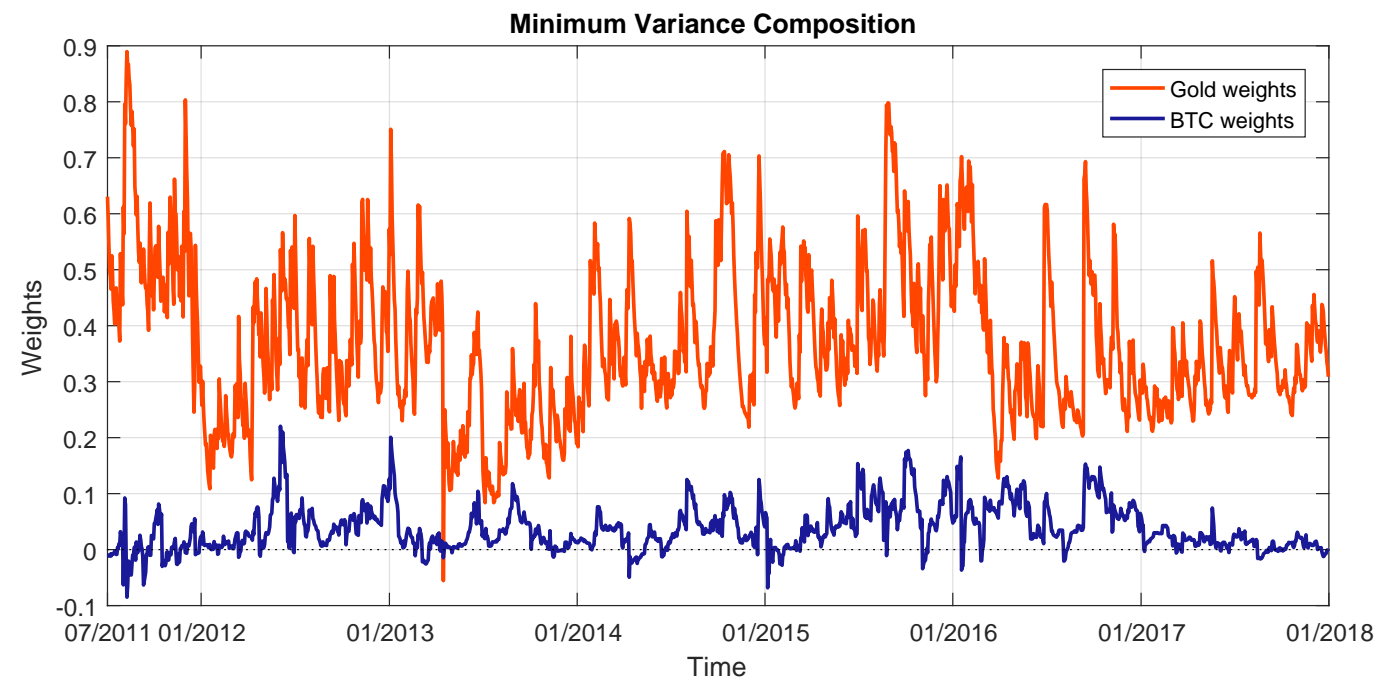

Figure 7: Time-varying weights of minimum-variance portfolios for Gold-S\&P 500 and Bitcoin-S\&P 500 based on BEKK correlations.

crix.hu-berlin.de. We synchronize the index series in the same fashion (e.g. excluding weekends) as before for the Bitcoin prices. Hence, we calculate 891 returns beginning August 1, 2014.

The descriptive statistics and the correlation matrix for CRIX are given in the Appendix in Tab. A.8 and Tab. A.9. The former are similar to those we present for Bitcoin. For the unconditional correlation, we find slight changes in comparison with Tab. 3 . Firstly, the pairwise correlation of Gold and the two MSCI indices is negative. Secondly, CRIX has a small negative correlation with the S\&P500 and MSCI EM50 returns. However, this only stems from the shorter sample period and might not be related to the choice of CRIX.

As Bitcoin has the largest share in CRIX, we obtain similar results for CRIX. We find significant asymmetries with APARCH in Tab. A.10. Interestingly, the estimations for FIAPARCH presented in Tab. A.11 might reveal spurious long memory (Walther et al. 2017). However, it is out of the scope of this paper to further address this issue.

The correlation of CRIX and global markets is almost identical than the reported relationship of Bitcoin. Despite a varying weight of Bitcoin in CRIX, with other cryptocurrencies such as Ethereum taking significant shares in the recent months, it appears that during times of market distress cryptocurrencies follow market movements. From the results for CRIX, we also conjecture that cryptocurrencies are highly correlated with each other, in particular when facing a general downward movement of equity markets.

Finally, we repeat our portfolio analysis with the cryptocurrency index CRIX. The results are given in Tab. 7. The corresponding portfolio weights for CRIX and the S\&P 500 are plotted in Fig. A.8. In contrast to Bitcoin, the CRIX seems to have marginal hedging effects for the three equity indices. During times of distress, portfolio returns are slightly better. However, comparing it with the hedging performance of Gold during that period, 
CRIX still fails to be considered an effective hedge. However, we highlight that in contrast to Bitcoin, CRIX offers some potential in view of portfolio volatility reduction. Comparing Panel $C$ of Tab. 6 and Tab. 7, we find that CRIX reduces the portfolio's volatility and slightly increases the overall return. Bitcoin also increases the portfolio return at the cost of an increased volatility. Although, it is important to note that Tab. 6] and Tab. 7 are based on a different time frame.

Table 7: Statistics for the minimum-variance portfolios for CRIX between Aug 1, 2014 and Dec 31, 2017.

\begin{tabular}{|c|c|c|c|c|c|c|c|c|c|}
\hline \multicolumn{10}{|c|}{ Panel A: Descriptive statistics of the portfolio weights } \\
\hline & \multicolumn{3}{|c|}{ S\&P 500} & \multicolumn{3}{|c|}{ MSCI World } & \multicolumn{3}{|c|}{ MSCI EM50 } \\
\hline & CRIX & \multicolumn{2}{|c|}{ Gold } & CRIX & \multicolumn{2}{|l|}{ Gold } & CRIX & \multicolumn{2}{|c|}{ Gold } \\
\hline Mean & 0.0530 & \multicolumn{2}{|c|}{0.4039} & 0.0421 & \multicolumn{2}{|c|}{0.3425} & 0.0724 & \multicolumn{2}{|c|}{0.5053} \\
\hline Std. Dev. & 0.0509 & \multicolumn{2}{|c|}{0.1275} & 0.0466 & \multicolumn{2}{|c|}{0.1332} & 0.0615 & \multicolumn{2}{|c|}{0.0956} \\
\hline Min. & -0.0951 & \multicolumn{2}{|c|}{0.1287} & -0.1175 & \multicolumn{2}{|c|}{0.1070} & -0.1012 & \multicolumn{2}{|c|}{0.3078} \\
\hline Max. & 0.2594 & \multicolumn{2}{|c|}{0.8131} & 0.2421 & \multicolumn{2}{|c|}{0.7813} & 0.2455 & \multicolumn{2}{|c|}{0.7847} \\
\hline \multicolumn{10}{|c|}{ Panel B: Value-at-Risk measures } \\
\hline & \multicolumn{3}{|c|}{ S\&P 500} & \multicolumn{3}{|c|}{ MSCI World } & \multicolumn{3}{|c|}{ MSCI EM50 } \\
\hline $\begin{array}{l}\operatorname{VaR}_{0.01} \\
\operatorname{VaR}_{0.05} \\
\operatorname{VaR}_{0.10} \\
\end{array}$ & \multicolumn{3}{|c|}{$\begin{array}{l}-2.1599 \\
-1.3051 \\
-0.8162\end{array}$} & \multicolumn{3}{|c|}{$\begin{array}{l}-2.0520 \\
-1.0624 \\
-0.7026\end{array}$} & \multicolumn{3}{|c|}{$\begin{array}{l}-2.6449 \\
-1.4866 \\
-1.0590 \\
\end{array}$} \\
\hline \multicolumn{10}{|c|}{ Panel C: Hedging Properties } \\
\hline & $\mathrm{S} \& \mathrm{P} 500$ & CRIX & Gold & MSCI World & CRIX & Gold & MSCI EM50 & CRIX & Gold \\
\hline Return & 0.0446 & 0.0507 & 0.0221 & 0.0324 & 0.0368 & 0.0203 & 0.0363 & 0.0530 & 0.0163 \\
\hline Volatility & 0.7637 & 0.7601 & 0.5053 & 0.6835 & 0.6810 & 0.4920 & 0.9009 & 0.8694 & 0.5914 \\
\hline Return|VaR 0.01 & -2.8932 & -3.0436 & -0.8847 & -2.7980 & -2.6341 & -0.8606 & -3.1531 & -2.7419 & -0.4558 \\
\hline Return|VaR 0.05 & -1.8702 & -1.8388 & -0.6936 & -1.6892 & -1.6474 & -0.6314 & -2.0633 & -1.8402 & -0.7102 \\
\hline Return|VaR 0.10 & -1.4450 & -1.4140 & -0.6137 & -1.2906 & -1.2344 & -0.6150 & -1.6555 & -1.4821 & -0.6961 \\
\hline
\end{tabular}

\section{Conclusion}

Based on recent data up to December 2017, we revisit the conditional volatility modeling of Bitcoin returns and update the results of previous applications of GARCH-class models on cryptocurrency prices. Our results indicate that the proper choice of the underlying distribution in these models is very important regarding the interpretation of identified stylized facts. In contrast to other studies, we find FIAPARCH to be the best fitting model in terms of log-likelihood and information criteria. This implies that Bitcoin returns have an asymmetric response to market shocks, which is of the same direction than precious metals. Price increases lead to an increase in volatility. Considering the extreme price increases observed for Bitcoin, this finding is not surprising. The high persistence of variance shocks, however, is the more dominating property and indicates that volatility declines slowly after an increase. In Bitcoin markets, we observed a tremendous rally in 2017 ending up with a major setback. These periods of elevated volatility lead to a higher persistence.

From a perspective of market linkages, our correlation modeling provides evidence that Bitcoin behaves completely different from Gold, in particular in market distress. While 
the flight-to-quality property of Gold is confirmed, Bitcoin shows a positive coupling effect and declines when markets are declining in shock-like situations. This is affirmed in a portfolio application which suggests that Bitcoin is no hedge against equity investments. However, our sample size is limited and we only observe a very small number of these downturns. Given the relatively young markets, this statement should be tested again in matured cryptocurrency markets. For now, Bitcoin as an asset does not resemble any other conventional asset from an econometric perspective. Our results hold for other cryptocurrencies and a short time period.

We believe that cryptocurrencies will remain highly volatile and continue to exhibit strong movements to both directions as future development stays highly unclear. Significant price movement of cryptocurrencies are dependent on several factors. First, cryptocurrencies will continue to experience large drops in price as investors will continue to take profit at the peak of price movement. Second, regulatory decisions will have a strong impact on investors' behavior. Currently, regulatory agencies are still weighing on a legal frame for cryptocurrencies. Third, in the face of recurring cyber attacks, such as on MtGox, Instawallet, or Bithump, the cryptocurrency ecosystem will have to strengthen its security standards to become accepted by traditional investors. 


\section{References}

Baillie, R. T. (1996). Long memory processes and fractional integration in econometrics. Journal of Econometrics, 73, 5-59. doi:10.1016/0304-4076(95)01732-1.

Bariviera, A. F., Basgall, M. J., Hasperué, W., \& Naiouf, M. (2017). Some stylized facts of the Bitcoin market. Physica A: Statistical Mechanics and its Applications, 484, 82-90. doi:10.1016/j.physa.2017.04.159.

Baur, D. G., Dimpfl, T., \& Kuck, K. (2017). Bitcoin, gold and the US dollar - A replication and extension. Finance Research Letters, forthcoming, . doi:10.1016/j.frl.2017.10. 012 .

Baur, D. G., \& Lucey, B. M. (2010). Is Gold a Hedge or a Safe Haven? An Analysis of Stocks, Bonds and Gold. Financial Review, 45, 217-229. doi:10.1111/j.1540-6288. 2010.00244.x.

Baur, D. G., \& McDermott, T. K. (2010). Is gold a safe haven? International evidence. Journal of Banking \& Finance, 34, 1886-1898. doi:10.1016/j.jbankfin.2009.12. 008 .

Baur, D. G., \& McDermott, T. K. (2016). Why is gold a safe haven? Journal of Behavioral and Experimental Finance, 10,63-71. doi:10.1016/j.jbef.2016.03.002.

Black, F. (1976). Studies of Stock Price Volatility Changes. In Proceedings of the Business and Economics Section of the American Statistical Association (p. 177-181).

Blau, B. M. (2017). Price dynamics and speculative trading in bitcoin. Research in International Business and Finance, 41, 493-499. doi:10.1016/j.ribaf .2017.05.010.

Bollerslev, T. (1986). Generalized autoregressive conditional heteroskedasticity. Journal of Econometrics, 31, 307-327. doi:10.1016/0304-4076(86)90063-1.

Bollerslev, T., Engle, R. F., \& Wooldridge, J. M. (1988). A Capital Asset Pricing Model with Time-varying Covariances. Journal of Political Economy, 96, 116-131.

Bollerslev, T., \& Mikkelsen, H. O. (1996). Modeling and pricing long memory in stock market volatility. Journal of Econometrics, 73, 151-184. doi:10.1016/0304-4076 (95) 01736-4.

Bouri, E., Gupta, R., Tiwari, A. K., \& Roubaud, D. (2017a). Does Bitcoin hedge global uncertainty? Evidence from wavelet-based quantile-in-quantile regressions. Finance Research Letters, 23, 87-95. doi:10.1016/j.frl.2017.02.009.

Bouri, E., Molnár, P., Azzi, G., Roubaud, D., \& Hagfors, L. I. (2017b). On the hedge and safe haven properties of Bitcoin: Is it really more than a diversifier? Finance Research Letters, 20, 192-198. doi:10.1016/j.frl.2016.09.025.

Brandvold, M., Molnár, P., Vagstad, K., \& Andreas Valstad, O. C. (2015). Price discovery on Bitcoin exchanges. Journal of International Financial Markets, Institutions and Money, 36, 18-35. doi:10.1016/j.intfin.2015.02.010. 
Campbell, J. Y., \& Hentschel, L. (1992). No news is good news. An asymmetric model of changing volatility in stock returns. Journal of Financial Economics, 31, 281-318. doi: $10.1016 / 0304-405 X(92) 90037-X$.

Capie, F., Mills, T. C., \& Wood, G. (2005). Gold as a hedge against the dollar. Journal of International Financial Markets, Institutions and Money, 15, 343-352. doi:10.1016/ j.intfin.2004.07.002.

Catania, L., \& Grassi, S. (2017). Modelling Crypto-Currencies Financial Time-Series. URL: https: //www.ssrn. com/abstract=3028486. doi:10.2139/ssrn.3028486.

Cheah, E. T., \& Fry, J. (2015). Speculative bubbles in Bitcoin markets? An empirical investigation into the fundamental value of Bitcoin. Economics Letters, 130, 32-36. doi: $10.1016 / \mathrm{j}$.econlet.2015.02.029.

Cheung, A. W.-K., Roca, E., \& Su, J.-J. (2015). Crypto-currency bubbles: an application of the Phillips-Shi-Yu (2013) methodology on Mt. Gox bitcoin prices. Applied Economics, 47, 2348-2358. doi:10.1080/00036846.2015.1005827.

Chkili, W., Hammoudeh, S., \& Nguyen, D. K. (2014). Volatility forecasting and risk management for commodity markets in the presence of asymmetry and long memory. Energy Economics, 41, 1-18. doi:10.1016/j.eneco.2013.10.011.

Christie, A. A. (1982). The stochastic behavior of common stock variances. Value, leverage and interest rate effects. Journal of Financial Economics, 10, 407-432. doi:10.1016/ 0304-405X (82) 90018-6.

Chu, J., Chan, S., Nadarajah, S., \& Osterrieder, J. (2017). GARCH Modelling of Cryptocurrencies. Journal of Risk and Financial Management, 10, 17. doi:10.3390/ jrfm10040017.

Chuen, D. L. K. (Ed.) (2015). Handbook of Digital Currency: Bitcoin, Innovation, Financial Instruments, and Big Data. London: Academic Press.

Ciaian, P., Rajcaniova, M., \& Kancs, D. (2017). Virtual relationships: Short- and longrun evidence from BitCoin and altcoin markets. Journal of International Financial Markets, Institutions and Money, 6, 467-486. doi:10.1016/j.intfin.2017.11.001.

Conrad, C., Custovic, A., \& Ghysels, E. (2018). Long-and Short-Term Cryptocurrency Volatility Components: A GARCH-MIDAS Analysis. Journal of Risk and Financial Management, 11, 1-12. doi:10.3390/jrfm11020023.

Corbet, S., Meegan, A., Larkin, C., Lucey, B., \& Yarovaya, L. (2018). Exploring the Dynamic Relationships between Cryptocurrencies and Other Financial Assets. Economics Letters, 165, 28-34. doi:10.1016/j.econlet.2018.01.004.

Davidson, J. (2004). Moment and Memory Properties of Linear Conditional Heteroscedasticity Models, and a New Model. Journal of Business \& Economic Statistics, 22, 16-29. doi:10.1198/073500103288619359.

Demir, E., Gozgor, G., Lau, C. K. M., \& Vigne, S. A. (2018). Does economic policy uncertainty predict the Bitcoin returns? An empirical investigation. Finance Research Letters, . doi:10.1016/j.frl.2018.01.005. 
Ding, Z., Granger, C. W. J., \& Engle, R. F. (1993). A long memory property of stock market returns and a new model. Journal of Empirical Finance, 1, 83-106. doi:10. 1016/0927-5398(93)90006-D.

Dwyer, G. P. (2015). The economics of Bitcoin and similar private digital currencies. Journal of Financial Stability, 17, 81-91. doi:10.1016/j.jfs.2014.11.006.

Dyhrberg, A. H. (2016). Bitcoin, gold and the dollar - A GARCH volatility analysis. Finance Research Letters, 16, 85-92. doi:10.1016/j.frl.2015.10.008.

Elendner, H., Trimborn, S., Ong, B., \& Lee, T. M. (2018). The Cross-Section of CryptoCurrencies as Financial Assets, Volume 1. In Handbook of Blockchain, Digital Finance, and Inclusion (pp. 145-173). Elsevier volume 649. doi:10.1016/B978-0-12-810441-5. 00007-5.

Engle, R. F. (1982). Autoregressive Conditional Heteroscedasticity with Estimates of the Variance of United Kingdom Inflation. Econometrica, 50, 987-1007. doi:10.2307/ 1912773 .

Engle, R. F. (2002). Dynamic Conditional Correlation. A Simple Class of Multivariate Generalized Autoregressive Conditional Heteroskedasticity Models, 20, 339-350. doi:10. $1198 / 073500102288618487$.

Engle, R. F., \& Kroner, K. F. . (1995). Multivariate Simultaneous Generalized Arch. Econometric Theory, 11, 122-150. doi:10.1017/S0266466600009063.

Engle, R. F., \& Ng, V. K. (1993). Measuring and Testing the Impact of News on Volatility. The Journal of Finance, 48, 1749-1778. doi:10.2307/2329066.

Guesmi, K., Saadi, S., Abid, I., \& Ftiti, Z. (2018). Portfolio diversification with virtual currency: Evidence from bitcoin. International Review of Financial Analysis, . doi:10. 1016/j.irfa.2018.03.004.

Hammoudeh, S. M., Yuan, Y., McAleer, M., \& Thompson, M. A. (2010). Precious metalsexchange rate volatility transmissions and hedging strategies. International Review of Economics \&6 Finance, 19, 633-647. doi:10.1016/j.iref.2010.02.003.

Härdle, W. K., Harvey, C. R., \& Reule, R. C. G. (2018). Understanding Cryptocurrencies?

Katsiampa, P. (2017). Volatility estimation for Bitcoin: A comparison of GARCH models. Economics Letters, 158, 3-6. doi:10.1016/j.econlet.2017.06.023.

Klein, T. (2017). Dynamic Correlation of Precious Metals and Flight-to-Quality in Developed Markets. Finance Research Letters, 23, 283-290. doi:10.1016/j.frl.2017. 05.002 .

Klein, T., \& Walther, T. (2017). Fast fractional differencing in modeling long memory of conditional variance for high-frequency data. Finance Research Letters, 22C, 274-279. doi:10.1016/j.frl.2016.12.020.

Kruse, R., Kaufmann, H., \& Wegener, C. (2018). Bias-corrected estimation for speculative bubbles in stock prices. Economic Modelling, forthc., 1-11. doi:10.1016/j.econmod. 2018.04.014. 
Nakamoto, S. (2008). Bitcoin: A Peer-to-Peer Electronic Cash System. URL: https: //bitcoin.org/bitcoin.pdf.

Savitzky, A., \& Golay, M. J. E. (1964). Smoothing and Differentiation of Data by Simplified Least Squares Procedures. Analytical Chemistry, 36, 1627-1639. doi:10.1021/ ac60214a047.

Trimborn, S., \& Härdle, W. K. (2016). CRIX an Index for blockchain based Currencies. URL: http://crix.hu-berlin.de/data/CRIXpaper.pdf.

Tse, Y. K. (1998). The conditional heteroscedasticity of the yen-dollar exchange rate. Journal of Applied Econometrics, 13, 49-55. doi:10.1002/(SICI) 1099-1255(199801/ 02) $13: 1<49:$ :AID-JAE459>3.0.CO;2-0.

Walther, T., Klein, T., Pham Thu, H., \& Piontek, K. (2017). True or spurious long memory in European Non-EMU currencies. Research in International Business and Finance, 40C, 217-230. doi:10.1016/j.ribaf.2017.01.003.

Zakoian, J. M. (1994). Threshold heteroskedastic models. Journal of Economic Dynamics and Control, 18, 931-955. doi:10.1016/0165-1889(94)90039-6. 


\section{Appendix A. Additional Figures and Tables for the Analysis of CRIX}

To be made available in the supplementary material.

Table A.8: Descriptive statistics for CRIX and financial daily return time series for Aug 1, 2014 to Dec $31,2017, n=891$ observations.

\begin{tabular}{|c|c|c|c|c|c|c|c|}
\hline & CRIX & Gold & Silver & WTI & S\&P 500 & MSCI World & MSCI EM50 \\
\hline Mean & 0.4346 & 0.0010 & -0.0210 & -0.0545 & 0.0446 & 0.0324 & 0.0363 \\
\hline Std. Dev. & 4.2001 & 0.8682 & 1.5136 & 2.5811 & 0.7637 & 0.6835 & 0.9009 \\
\hline Min. & -23.8364 & -3.1910 & -7.7286 & -10.7263 & -4.0182 & -5.0273 & -4.4552 \\
\hline Max. & 19.8541 & 4.1964 & 5.4035 & 11.6213 & 3.8369 & 2.5681 & 3.4746 \\
\hline Skewness & -0.3455 & 0.2366 & -0.3274 & 0.1405 & -0.3599 & -0.8015 & -0.3213 \\
\hline Kurtosis & 9.0743 & 5.2371 & 5.9894 & 5.0188 & 6.4371 & 8.6975 & 4.5726 \\
\hline Jarque Bera & $1387.5104^{* * *}$ & $194.1075^{* * *}$ & $347.6768^{* * *}$ & $154.2378^{* * *}$ & $457.8316^{* * *}$ & $1300.5326^{* * *}$ & $107.1454^{* * *}$ \\
\hline Ljung Box (25) & $40.2952^{* *}$ & $49.3313^{* * *}$ & $49.8255^{* * *}$ & 28.6566 & 25.4508 & $53.6869^{* * *}$ & $46.8096^{* * *}$ \\
\hline ARCH (25) & $94.8775^{* * *}$ & $64.4326^{* * *}$ & $40.2444^{* *}$ & $114.1034^{* * *}$ & $169.5419^{* * *}$ & $100.7778^{* * *}$ & $111.2621^{* * *}$ \\
\hline $\mathrm{ADF}$ & $-28.9508^{* * *}$ & $-30.3975^{* * *}$ & $-31.0810^{* * *}$ & $-33.2704^{* * *}$ & $-30.0854^{* * *}$ & $-25.5438^{* * *}$ & $-24.8281^{* * *}$ \\
\hline
\end{tabular}

Note: Std. Dev. is the standard deviation, Min. and Max. are minimum and maximum of the time series. ARCH(25) is the test for autoregressive conditional heteroskedasticity by Engle (1982) at the 25th lag. ADF is the Augmented Dickey-Fuller test for unit root.

Table A.9: Unconditional pairwise Pearson correlation matrix for the sample period Aug 1, 2014 to Dec $31,2017$.

\begin{tabular}{l|ccccccc}
\hline & CRIX & Gold & Silver & WTI & S\&P 500 & MSCI World & MSCI EM50 \\
\hline CRIX & \multirow{2}{*}{1.0000} & 0.0438 & 0.0044 & 0.0272 & -0.0028 & 0.0046 & -0.0139 \\
Gold & & 1.0000 & 0.6644 & 0.0150 & -0.1612 & -0.1107 & -0.0922 \\
Silver & & & 1.0000 & 0.1606 & 0.0092 & 0.1023 & 0.1014 \\
WTI & & & & 1.0000 & 0.3013 & 0.3296 & 0.2064 \\
S\&P 500 & & & & & 1.0000 & 0.9087 & 0.4599 \\
MSCI World & & & & & & 1.0000 & 0.6235 \\
MSCI EM50 & & & & & & & 1.0000 \\
\hline
\end{tabular}


Table A.10: Estimation results from APARCH model with $n=891$ observations (Aug 1, 2014-Dec 31, 2017). Statistically significant parameters are indicated with asterisk *, **, *** for $10 \%, 5 \%$, and $1 \%$ level of significance.

\begin{tabular}{|c|c|c|c|c|c|c|c|}
\hline & CRIX & Gold & Silver & WTI & S\&P 500 & MSCI World & MSCI EM50 \\
\hline$\theta_{0}$ & $0.4094^{* * *}$ & -0.0101 & 0.0182 & $-0.0863^{* * *}$ & $0.0544^{* *}$ & $0.0332^{* * *}$ & 0.0247 \\
\hline$\theta_{1}$ & $-0.0386^{* * *}$ & -0.0050 & -0.0279 & $-0.1186^{* * *}$ & $-0.0903^{* *}$ & $0.0661^{* *}$ & $0.2099^{* * *}$ \\
\hline$\omega$ & $0.0967^{* * *}$ & 0.0030 & 0.0000 & $0.0139^{* * *}$ & $0.0379^{* * *}$ & $0.0231^{* *}$ & $0.0716^{*}$ \\
\hline$\alpha$ & $0.2004^{* * *}$ & 0.0277 & 0.0017 & $0.0240^{* * *}$ & $0.1358^{* * *}$ & $0.1057^{* * *}$ & $0.0986^{*}$ \\
\hline$\beta$ & $0.7996^{* * *}$ & $0.9709^{* * *}$ & $0.9941^{* * *}$ & $0.9760^{* * *}$ & $0.8641^{* * *}$ & $0.8943^{* * *}$ & $0.7891^{* * *}$ \\
\hline$\gamma$ & -0.1614 & 0.0796 & -0.9995 & $0.9995^{* * *}$ & $0.9995^{* * *}$ & $0.9995^{* * *}$ & $0.5615^{* *}$ \\
\hline$\delta$ & $0.4354^{* * *}$ & $1.9657^{* * *}$ & $2.7273^{* * *}$ & $0.3106^{* * *}$ & $0.7967^{* * *}$ & $0.8513^{* * *}$ & $1.8599^{* * *}$ \\
\hline$\nu$ & $3.0187^{* * *}$ & $4.2659^{* * *}$ & $2.8387^{* * *}$ & $10.6260^{* * *}$ & $4.6021^{* * *}$ & $5.5958^{* * *}$ & $15.4109^{* *}$ \\
\hline $\mathrm{LL}$ & -2289.63 & -1084.49 & -1552.74 & -1993.37 & -835.36 & -742.49 & -1092.35 \\
\hline $\mathrm{BIC}$ & 4633.60 & 2223.31 & 3159.82 & 4041.08 & 1725.05 & 1539.32 & 2239.04 \\
\hline Jarque Bera & $4102.8546^{* * *}$ & $141.7671^{* * *}$ & $287.3423^{* * *}$ & $23.7308^{* * *}$ & $569.9882^{* * *}$ & $1308.3212^{* * *}$ & $19.8160^{* * *}$ \\
\hline Ljung Box (25) & $48.0789^{* * *}$ & $52.0254^{* * *}$ & $46.0625^{* * *}$ & 12.0729 & 27.0364 & 23.9060 & 17.7446 \\
\hline ARCH (25) & $51.4380^{* * *}$ & 26.1708 & $34.5267^{*}$ & 18.9056 & $48.9345^{* * *}$ & 33.5821 & 21.4819 \\
\hline
\end{tabular}

Table A.11: Estimation results from FIAPARCH model with $n=891$ observations (Aug 1, 2014-Dec 31, 2017). Statistically significant parameters are indicated with asterisk *, **, *** for $10 \%, 5 \%$, and $1 \%$ level of significance.

\begin{tabular}{|c|c|c|c|c|c|c|c|}
\hline & CRIX & Gold & Silver & WTI & S\&P 500 & MSCI World & MSCI EM50 \\
\hline$\theta_{0}$ & $0.3638^{* * *}$ & -0.0103 & 0.0048 & $-0.1275^{* * *}$ & $0.0523^{* * *}$ & $0.0297^{*}$ & 0.0196 \\
\hline$\theta_{1}$ & $-0.0268^{* * *}$ & -0.0065 & -0.0312 & $-0.1087^{* * *}$ & $-0.0996^{* * *}$ & $0.0662^{* *}$ & $0.1996^{* * *}$ \\
\hline$\omega$ & $0.3807^{* *}$ & 0.1658 & 1.0860 & $0.4569^{*}$ & $0.2518^{* * *}$ & $0.1464^{* * *}$ & $0.2278^{* * *}$ \\
\hline$\alpha$ & 0.0193 & 0.2635 & 0.4377 & 0.0778 & $0.0011^{* * *}$ & 0.0383 & 0.0000 \\
\hline$d$ & $0.7712^{* * *}$ & 0.2651 & 0.1245 & $0.8380^{* *}$ & $0.9776^{* * *}$ & $0.5146^{* * *}$ & $0.3114^{* * *}$ \\
\hline$\beta$ & $0.7042^{* * *}$ & 0.5286 & 0.5278 & $0.9154^{* * *}$ & $0.8296^{* * *}$ & $0.4738^{* *}$ & $0.2914^{* * *}$ \\
\hline$\gamma$ & $-0.2504^{*}$ & -0.1291 & -0.2770 & $0.9125^{* * *}$ & $0.9701^{* * *}$ & $0.8704^{* * *}$ & $0.5702^{* * *}$ \\
\hline$\delta$ & $0.2467^{* *}$ & $2.0700^{*}$ & 3.0000 & 0.3692 & $0.8543^{* * *}$ & $1.1052^{* * *}$ & $1.2969^{* * *}$ \\
\hline$\nu$ & $2.3793^{* * *}$ & $4.3169^{* * *}$ & $2.9682^{* * *}$ & 14.6145 & $5.1972^{* * *}$ & $6.1522^{* * *}$ & $16.4508^{*}$ \\
\hline $\mathrm{LL}$ & -2282.66 & -1086.49 & -1552.76 & -1997.29 & -826.14 & -740.58 & -1092.82 \\
\hline $\mathrm{BIC}$ & 4626.45 & 2234.10 & 3166.65 & 4055.71 & 1713.41 & 1542.29 & 2246.77 \\
\hline Jarque Bera & $2807.9919^{* * *}$ & $135.6287^{* * *}$ & $364.5237^{* * *}$ & $44.1969^{* * *}$ & $532.0118^{* * *}$ & $2397.7887^{* * *}$ & $15.3015^{* * *}$ \\
\hline Ljung Box (25) & $42.4010^{* *}$ & $50.3412^{* * *}$ & $43.1643^{* *}$ & 11.9732 & 25.6216 & 21.7947 & 17.0946 \\
\hline $\mathrm{ARCH}(25)$ & $62.3583^{* * *}$ & 19.9310 & 29.2771 & 22.3528 & 13.4596 & 9.2813 & 27.0943 \\
\hline
\end{tabular}

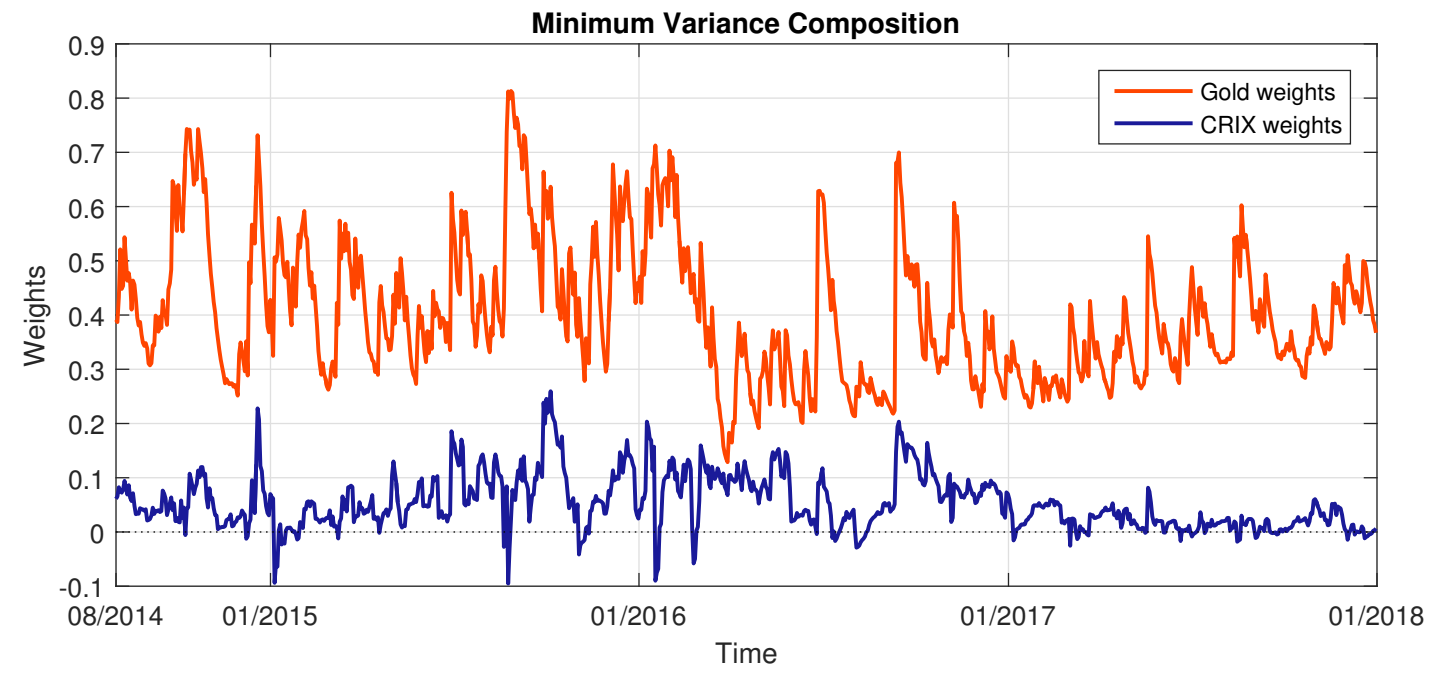

Figure A.8: Time-varying weights of minimum-variance portfolios for Gold-S\&P 500 and CRIX-S\&P 500 based on BEKK correlations. 


\section{Appendix B. Additional Figures}

To be made available online.

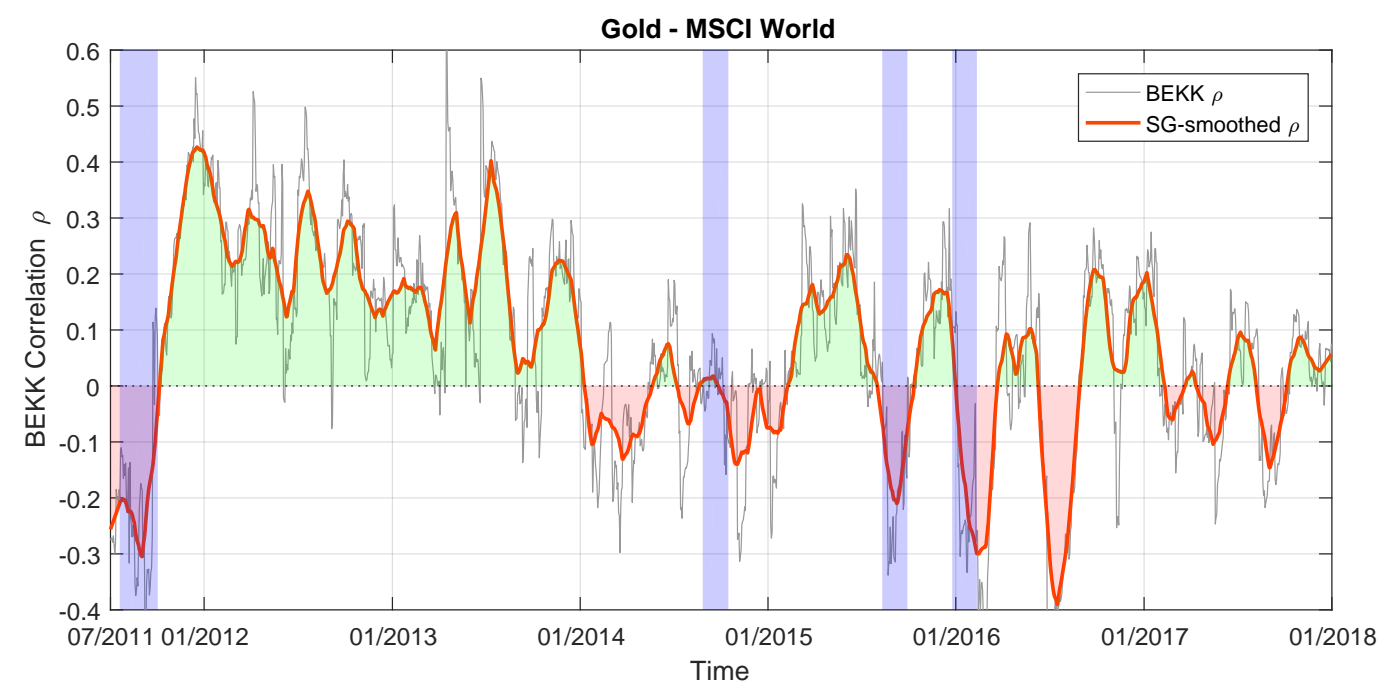

Figure B.9: Dynamic correlations of Gold and MSCI World returns obtained with the BEKK-GARCH between July 2, 2011 and December 31, 2017, $n=1695$. Unfiltered correlations are plotted in gray, Savitzky-Golay-smoothing is plotted in red. Times of market distress is highlighted in blue.

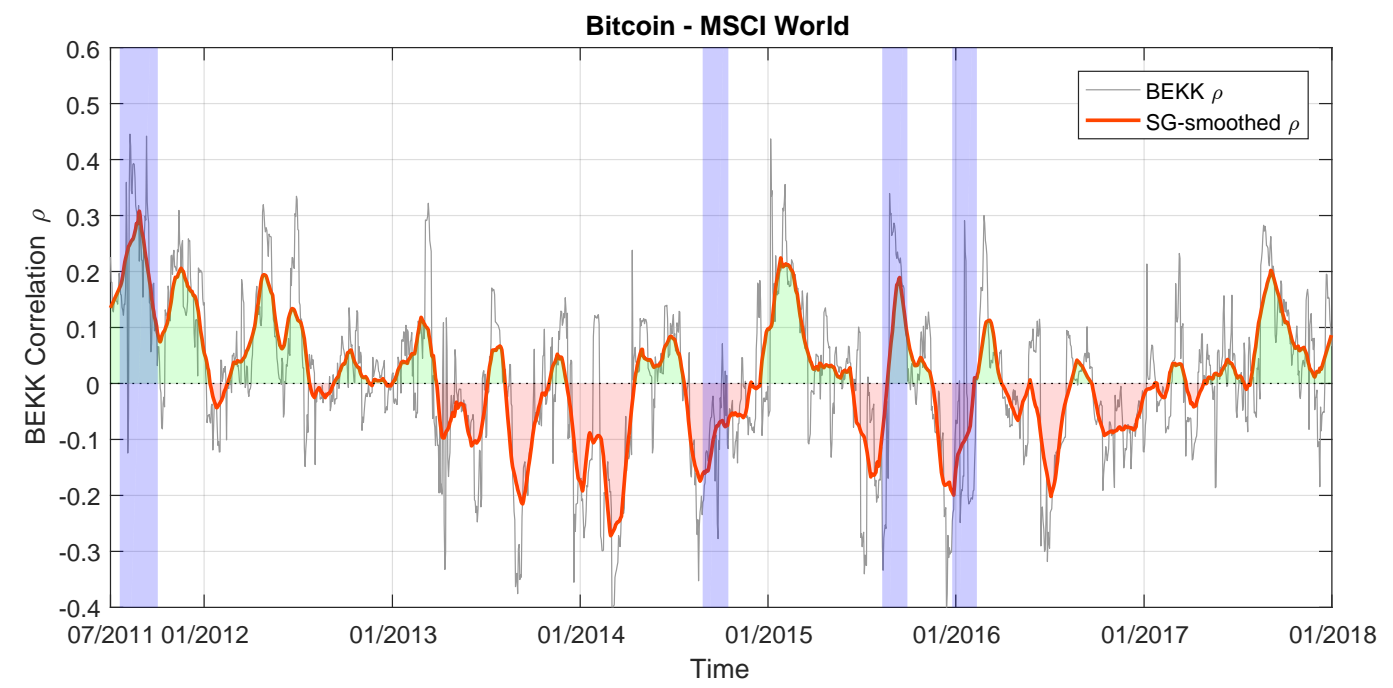

Figure B.10: Dynamic correlations of Bitcoin and MSCI World returns obtained with the BEKK-GARCH between July 2, 2011 and December 31, 2017, $n=1695$. Unfiltered correlations are plotted in gray, Savitzky-Golay-smoothing is plotted in red. Times of market distress is highlighted in blue. 


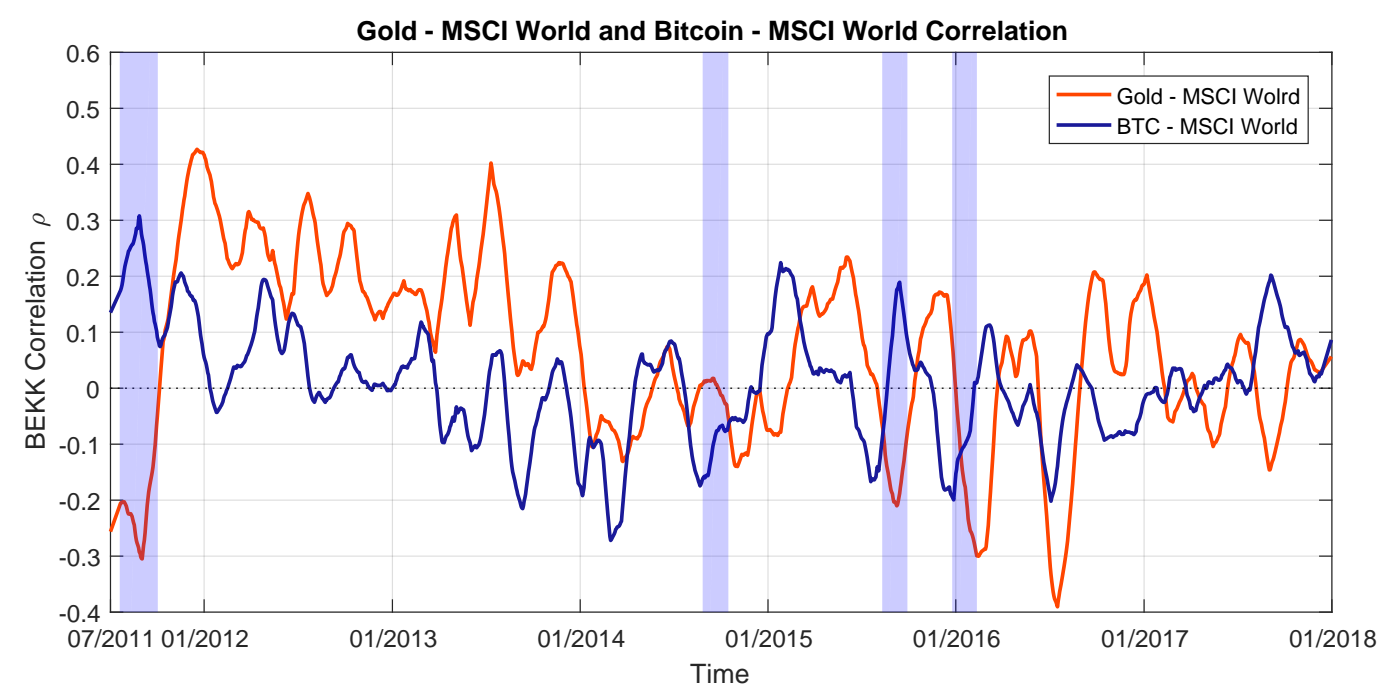

Figure B.11: Smoothed correlations of Bitcoin and Gold returns with MSCI World returns obtained with the BEKK-GARCH between July 2, 2011 and December 31, 2017, $n=1695$. Times of market distress is highlighted in blue.

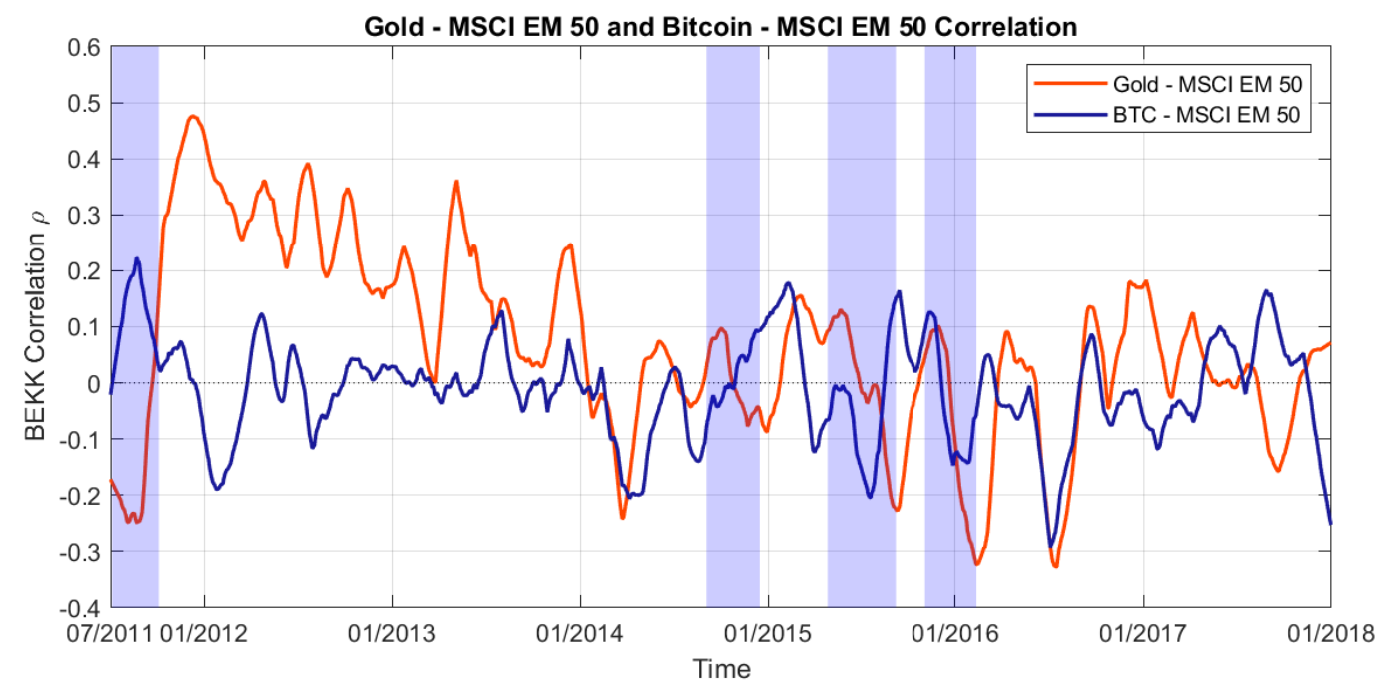

Figure B.12: Smoothed correlations of Bitcoin and Gold returns with MSCI EM50 returns obtained with the BEKK-GARCH between July 2, 2011 and December 31, 2017, $n=1695$. Times of market distress is highlighted in blue. 


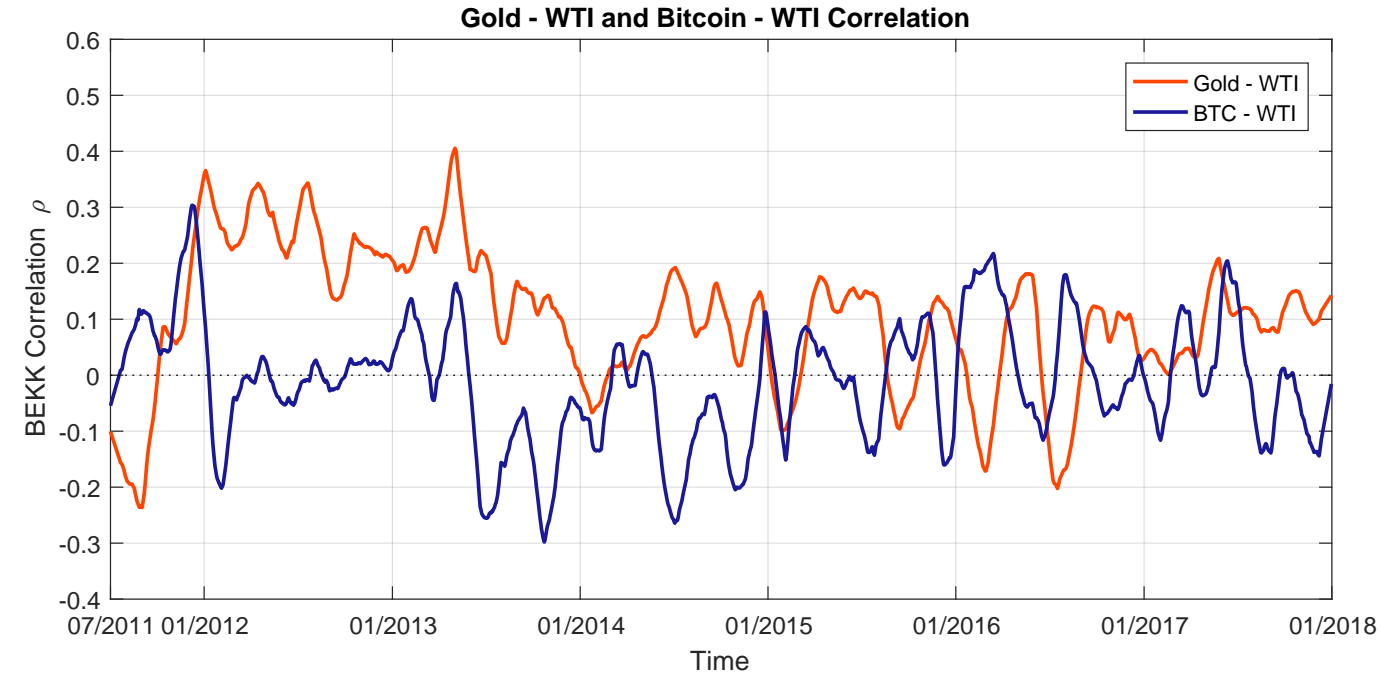

Figure B.13: Smoothed correlations of Bitcoin and Gold returns with WTI returns obtained with the BEKK-GARCH between July 2, 2011 and December 31, 2017, $n=1695$. Times of market distress is highlighted in blue. 